Review

\title{
Applying the adverse outcome pathway (AOP) for food sensitization to support in vitro testing strategies
}

\author{
Daniel Lozano-Ojalvo ${ }^{\mathrm{a}, *}$, Sara Benedéb ${ }^{\text {, Celia M. Antunes }}{ }^{\mathrm{c}}$, Simona L. Bavaro ${ }^{\mathrm{d}}$, \\ Grégory Bouchaud ${ }^{\mathrm{e}}$, Ana Costa ${ }^{\mathrm{c}}$, Sandra Denery-Papini ${ }^{\mathrm{e}}$, Araceli Díaz-Perales ${ }^{\mathrm{f}}$, \\ María Garrido-Arandia ${ }^{\mathrm{f}}$, Marija Gavrovic-Jankulovic ${ }^{\mathrm{g}}$, Simone Hayen ${ }^{\mathrm{h}}$, Mónica Martínez-Blanco ${ }^{\mathrm{i}}$, \\ Elena Molina ${ }^{\mathrm{i}}$, Linda Monaci ${ }^{\mathrm{d}}$, Raymond H.H. Pieters ${ }^{\mathrm{j}}$, Clelia Villemin ${ }^{\mathrm{e}}$, Harry J. Wichers ${ }^{\mathrm{k}}$,

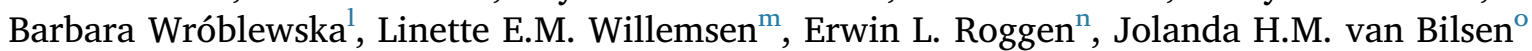

${ }^{a}$ Immunology Institute, Jaffe Food Allergy Institute, Icahn School of Medicine at Mount Sinai, New York, NY, USA

${ }^{\mathrm{b}}$ Universidad Complutense de Madrid, Madrid, Spain

${ }^{\mathrm{c}}$ University of Evora, Evora, Portugal

${ }^{\mathrm{d}}$ Institute of Sciences of Food Production, CNR, Bari, Italy

e INRA, UR1268 BIA, Nantes, France

${ }^{\mathrm{f}}$ Centro de Biotecnología y Genómica de Plantas, UPM-INIA, Madrid, Spain

${ }^{\mathrm{g}}$ Faculty of Chemistry, University of Belgrade, Belgrade, Serbia

${ }^{\mathrm{h}}$ Utrecht University, Utrecht, the Netherlands

i Instituto de Investigación en Ciencias de la Alimentación, CSIC-UAM, Madrid, Spain

${ }^{\mathrm{j}}$ Utrecht University and Utrecht University of Applied Sciences, Utrecht, the Netherlands

${ }^{\mathrm{k}}$ Wageningen University and Research, Wageningen, the Netherlands

${ }^{1}$ Institute of Animal Reproduction and Food Research, PAN, Olsztyn, Poland

${ }^{\mathrm{m}}$ Division of Pharmacology, Utrecht University, Utrecht, the Netherlands

${ }^{\mathrm{n}}$ 3Rs Managing and Consulting ApS, Lyngby, Denmark

${ }^{\circ}$ TNO, Zeist, the Netherlands

\section{A R T I C L E I N F O}

\section{Keywords:}

IgE-mediated food allergy

Adverse outcome pathway

In vitro models

Epithelial cells

Dendritic cells

$\mathrm{T}$ and $\mathrm{B}$ cells

\begin{abstract}
A B S T R A C T
Background: Before introducing proteins from new or alternative dietary sources into the market, a compressive risk assessment including food allergic sensitization should be carried out in order to ensure their safety. We have recently proposed the adverse outcome pathway (AOP) concept to structure the current mechanistic understanding of the molecular and cellular pathways evidenced to drive IgE-mediated food allergies. This AOP framework offers the biological context to collect and structure existing in vitro methods and to identify missing assays to evaluate sensitizing potential of food proteins.

Scope and approach: In this review, we provide a state-of-the-art overview of available in vitro approaches for assessing the sensitizing potential of food proteins, including their strengths and limitations. These approaches are structured by their potential to evaluate the molecular initiating and key events driving food sensitization. Key findings and conclusions: The application of the AOP framework offers the opportunity to anchor existing testing methods to specific building blocks of the AOP for food sensitization. In general, in vitro methods evaluating mechanisms involved in the innate immune response are easier to address than assays addressing the adaptive immune response due to the low precursor frequency of allergen-specific $\mathrm{T}$ and B cells. Novel ex vivo culture strategies may have the potential to become useful tools for investigating the sensitizing potential of food proteins. When applied in the context of an integrated testing strategy, the described approaches may reduce, if not replace, current animal testing approaches.
\end{abstract}

\footnotetext{
${ }^{*}$ Corresponding author.

E-mail addresses: daniel.lozano-ojalvo@mssm.edu (D. Lozano-Ojalvo), s.benede@csic.es (S. Benedé), cmma@uevora.pt (C.M. Antunes), simona.bavaro@ispa.cnr.it (S.L. Bavaro), gregory.bouchaud@inra.fr (G. Bouchaud), acrc@uevora.pt (A. Costa), sandra.denery@inra.fr (S. Denery-Papini), araceli.diaz@upm.es (A. Díaz-Perales), maria.garrido@upm.es (M. Garrido-Arandia), mgavrov@chem.bg.ac.rs (M. Gavrovic-Jankulovic), S.M.Hayen@uu.nl (S. Hayen), m.martinez.blanco@csic.es (M. Martínez-Blanco), e.molina@csic.es (E. Molina), linda.monaci@ispa.cnr.it (L. Monaci),

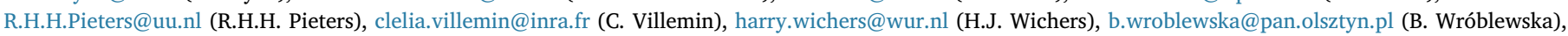
l.e.m.willemsen@uu.nl (L.E.M. Willemsen),3rsmc.eu@gmail.com (E.L. Roggen), j.vanbilsen@tno.nl (J.H.M. van Bilsen).
} 


\section{Introduction}

Food allergy is one of the most common health disorders in the western world. The occurrence of food allergy drastically increased in the last decades with a current prevalence that reaches up to $10 \%$ of the population (Sicherer \& Sampson, 2018). Food allergies are adverse reactions to an otherwise harmless food or food component that involves an abnormal response of the body's immune system to specific protein (s) in food. The clinical picture of food allergy is pleiomorphic and can range from gastrointestinal symptoms to severe anaphylaxis (Eigenmann et al., 2008). Most (approximately 90\%) of food allergic reactions are caused by milk, egg, peanuts, tree nuts, fish, soya, wheat and shell fish (Boyce, Assa, Burks, Jones, \& Hugh, 2010). Allergic disease develops in a two-step process comprising sensitization to the allergenic food and subsequent elicitation of the allergic reaction resulting in symptoms on re-exposure to the allergen.

The contribution of food proteins to healthy aging is increasingly documented and the role of these proteins in a healthy diet recognized. However, a growing global population places an increased pressure on the world's resources to provide not only more but also different types of food. The development and introduction of new dietary protein sources has the potential to improve food supply sustainability. This can be achieved via different ways, e.g. through development of new nutritional/protein sources, improvement of crops, by providing solutions to technical challenges during manufacturing, as well as by valorizing unused side products (Remington et al., 2018; Selb et al., 2017). These foods must not pose a risk to public health, thus a comprehensive risk assessment should be conducted in order to ensure their safety. Risk assessment should cover different domains including kinetics, toxicology, nutritional effects and allergenicity (de Boer \& Bast, 2018).

Studying the allergenicity of these foods is quite complex. Firstly, relevant allergenic testing material needs to be obtained. To this end, several factors (e.g. pH, buffer, fatty substances in matrix etc), should be taken into consideration to obtain an extract that provides a good picture of the novel food, which have to be optimized case-by-case (Mazzucchelli et al., 2018). In addition, the purification of proteins might also be also technically challenging and may result in chemical modifications, which needs to be assessed prior to testing for allergenicity (Mazzucchelli et al., 2018). Next to the difficulties to obtain relevant allergenic testing material, it is evident that properties of food matrix components are also relevant and important in the sensitization process. The allergen is never in initial contact with the immune system in a purified state; the matrix surrounds, interacts with, and can affect the physiochemical features of the allergens. Currently, the primary influences of the matrix are thought to be antigen bioavailability and release, digestibility and interactions with the immune system (McClain, Bowman, Fernández-Rivas, Ladics, \& Van Ree, 2014). However there are no straightforward approaches to address the many variables represented by the matrix components in food (reviewed by McClain et al., 2014), so additional knowledge is required which will help to develop tools to incorporate their influence on sensitization into model systems (van Bilsen et al., 2017).

This manuscript focusses on the current available in vitro tools to study cellular and molecular mechanisms driving the non-symptomatic sensitization phase of food allergy resulting in the generation of food protein-specific IgE.

There are a considerable number of in vivo and in vitro data available describing molecular and cellular events potentially involved in food sensitization. Recently, these events have been organized in a sequence of related processes that is plausible to result in sensitization and useful to challenge current hypothesis by applying the concept of adverse outcome pathway (AOP) (van Bilsen et al., 2017). The proposed AOP framework provides a simplification of a complex biological process by collecting, organizing and evaluating data that describe the events of an adverse outcome at a biological level of organization with relevance for risk assessment. The application of the AOP concept allows to identify the major molecular initiating events (MIE) and key events (KE) underlying food sensitization (Fig. 1). The AOP for food sensitization starts with a MIE involving the allergen uptake over the mucosal barrier of the gut intestine. The food protein passage may induce the activation of intestinal epithelial cells (IECs), representing KE1, followed by the local activation of dendritic cells (DCs) and their migration to the mesenteric lymph nodes (KE2 and KE3). There, DCs present processed allergen to naive $\mathrm{T}$ cells priming them toward a T helper type 2 (Th2) response (KE4). Thus these events may cause the activation of B cells (KE5) and the production of specific IgE by plasma cells.

The events included in this AOP are still highly complex at molecular/cellular level, but the challenge is to integrate MIE and KE to better understand the mechanistic pathways of food sensitization induction. The AOP for food allergy offers the opportunity to anchor existing methods for the testing and assessment of sensitizing potential of food proteins. Moreover, it gives insight into which specific assays are suitable to evaluate the influence of novel food proteins and ingredients in the sensitization process.

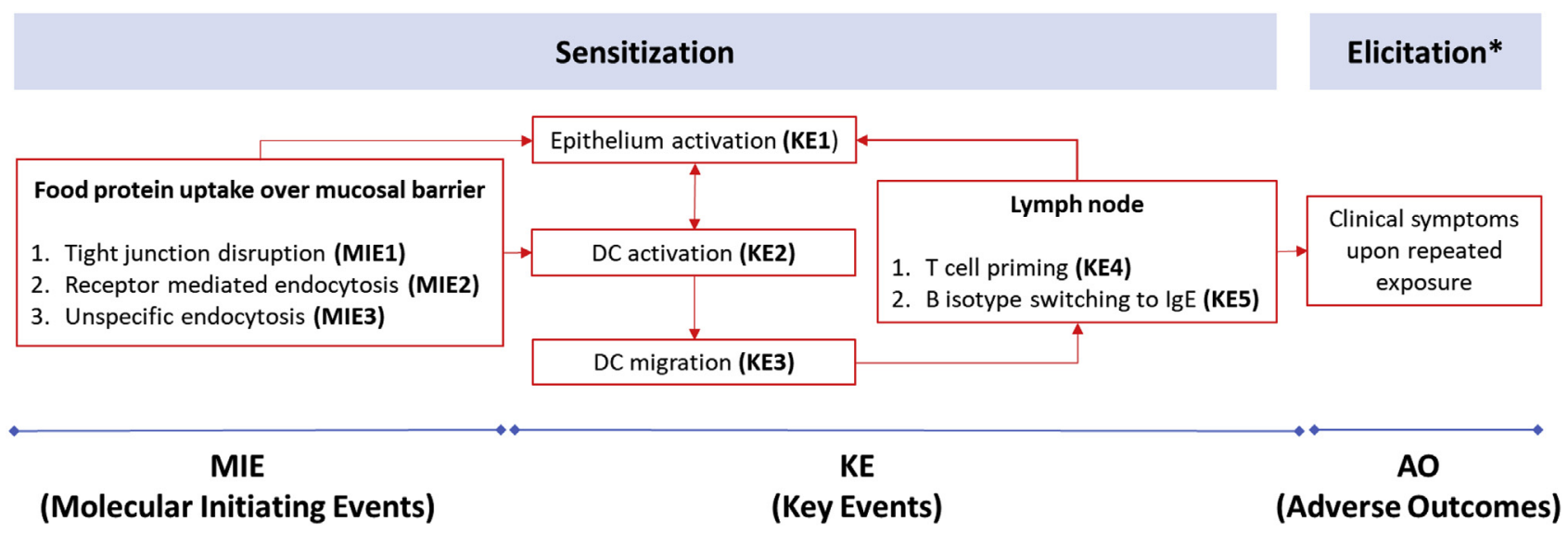

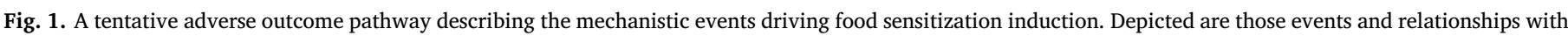

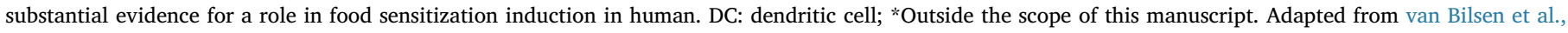
2017. 
It is still a matter of debate whether human, like mice, can be sensitized via other routes than the oral route such as via the skin or respiratory route. Epidemiological studies in human populations seem to confirm the skin as a relevant route for food sensitization induction and allergy in humans, however is mechanistically not sufficiently understood yet (van Bilsen et al., 2017). Evidence for the respiratory route is even more ambiguous (van Bilsen et al., 2017). Therefore, in vitro testing strategies focusing on the dermal or respiratory route are not explored in this review.

In this review, we aim to provide the state-of-the-art of existing in vitro approaches for assessing sensitizing potential of food proteins based on the identified MIE and KE proposed in the AOP for food sensitization, as described by van Bilsen et al. (van Bilsen et al., 2017). For this propose, we provide cell assays previously used for the study of food allergens focusing on major read-outs as well as strengths and limitations of these assays.

\section{Antigen uptake over intestinal mucosal barrier and epithelium activation}

\subsection{In vitro models to assess tight junction disruption (MIE1)}

During the gastrointestinal digestion, intact proteins and peptide fragments reach the intestinal lumen where they interact with the IECs resulting in antigen uptake over the gut barrier. Digestion products may be transferred across the intestinal epithelium by paracellular transport driven by disruption of tight junctions, adherent junctions and desmosomes, representing MIE1. Tight junctions are multiprotein complexes composed by transmembrane proteins (occludin, claudin, junctional adhesion molecule A and tricellulin) that provide the integrity of the actomyosin ring, which controls inter-epithelial permeability.

Typically, epithelial in vitro models employed to study the transport and absorption of food proteins or peptides along the intestinal epithelium are based on cell lines (including Caco-2, HT-29, T84, and IPEC-J2) grown in a transwell system (Cubells-Baeza et al., 2015). In this regard, Grozdanovic and co-workers demonstrated that the exposure of T84 cells to actinidin, a kiwifruit cysteine protease, resulted in the impairment of the epithelial barrier, due to the degradation of occludin promoted by the proteolytic action of actinidin (Grozdanovic et al., 2016). As a consequence, an increase of the intestinal permeability was recorded which could contribute to the process of sensitization in kiwifruit allergy. By employing the Caco-2 cell model, Price et al. showed that peanut allergens Ara h 1 and Ara h 2 were able to alter the intestinal barrier permeability, modifying the co-localization of the transmembrane tight junction proteins occludin, JAM-A and claudin-1, with the intracellular adhesion protein ZO-1 (Price, Ackland, Burks, Knight, \& Suphioglu, 2014). In another study, $\beta$-conglycinin from soy (Gly $\mathrm{m} 5$ ) induced a downregulation of tight junction proteins by using a model of IPEC-J2 porcine cells (Zhao et al., 2015).

On the other hand, the breach of epithelial barrier may be a consequence of Th2 switching and may possibly reflect the abnormal responses and vicious cycle triggered by mast cell activation. It has been observed that mast cells releasing chymases and histamine have an impact on the physiology of the intestinal mucosa, promoting the degradation of the tight junction occludins (Bischoff \& Kramer, 2007). Moreover, mast cells are involved in the release of Th2-realted cytokines, such as IL-4 and IL-13, that influence the modulation of IEC permeability in different human IEC cultures, decreasing the transepithelial electrical resistance (TEER) and selectively increasing the apical-to-basal movement of proteins (Ceponis, Botelho, Richards, \& McKay, 2000). In order to address the integrity of the intestinal monolayer, the study of the TEER is an important issue that provides information about the inter-epithelial transport, generally associated with an alteration of the tight junctions and thus relates to paracellular transport. It has been reported that exposure of crude apple homogenate produces an increase of the paracellular resistance in Caco-
2 cells, with an augmentation of the expression of several tight junction related genes, including claudin 4 (Vreeburg, Bastiaan-Net, \& Mes, 2011). Zhao et al. have recently shown that peptides produced during simulated in vitro digestion of soybean $\beta$-conglycinin, determine an increase of alkaline phosphatase activity with a decrease of mitochondrial respiration (MTT assay), TEER values and downregulation of claudin-3, claudin-4, occludin, and ZO-1 expression (Zhao, Liu, Zhang, Pan, \& Qin, 2017).

However, not all food allergens affect TEER resistance. Moreno et al. reported that the transcellular transport of purified $2 \mathrm{~s}$ albumins Ber e 1 (brazil nut) and Ses i 1 (sesame seed) across Caco-2 monolayer did not affect the permeability as assessed by the absence of any change of allergen absorption rate and TEER values (Moreno, Rubio, Olano, \& Clemente, 2006). In other work, authors found that hydrolyzed ovalbumin did not affect MTT values or cell permeability indicating a protective effect exerted by the food matrix on the cell barrier (Grootaert et al., 2017). In addition, TEER values were restored to their original levels, demonstrating the absence of any permanent damage on the monolayer caused by egg digests tested (Grootaert et al., 2017). In line with this, previous studies also reported that purified proteins from wheat ( $\omega 5$-gliadin and LTP 1) (Bodinier et al., 2007), peach (Pru p 3 and LTP 1) (Tordesillas et al., 2013), and peanut (Ara h 1 and Ara h 2) (Price, Ackland, \& Suphioglu, 2017) were able to cross Caco-2 monolayers without compromising cell monolayer integrity.

\subsection{In vitro models to assess receptor-mediated and unspecific endocytosis (MIE2 and MIE3)}

Apart from paracellular transport, food proteins may also cross the intestinal epithelium via transcellular transport pathways, either receptor-mediated (e.g. CD23, the low affinity FceRII-IgE receptor) (MIE2) or via unspecific endocytosis (MIE3).

CD23 is expressed by Caco-2, T84 and HT29 cells and their expression can be stimulated by IL-4 (Tu et al., 2005). Using Caco- 2 cells, it has been demonstrated that IgE-antigen (nitrophenyl(NP)-BSA) complexes trigger the upregulation of IL-8 and CCL20. The supernatant of such triggered Caco-2 cells induced DC migration in a CCL20-dependent manner (Li et al., 2007). In HT29 cells, it has been shown that CD23 expression and transcellular transport of IgE-NP-ovalbumin complexes could be stimulated by factors present in supernatant of activated mast cell (HMC1) and monocyte (THP1) lines (Tu, Oluwole, Struiksma, Perdue, \& Yang, 2009). The role of SIgA in transcytosis has been studied even less than that of CD23, and mainly focus on gliadin peptides. Caco-2 and HT29 cells express CD71 and transglutaminase 2 (TG2), both shown to co-precipitate with SIgA and important for endosomal transport routing (Lebreton et al., 2012). These reports on receptor-mediated endocytosis are from a few isolated studies, but they show that the role of CD23-mediated and of CD71/TG2 transcytosis could be examined using in vitro models, although more food proteins using these assays should be tested.

Unspecific transport of food proteins may occur via epithelial, goblet or M cells and may result not only in protein degradation within these cells and cellular activation, but also it can lead to process of proteins into peptides that can be expressed in the context of MHC-II. The route of uptake seems to have an important implication for the final outcome. Although insufficiently studied, it has been proposed that larger cross-linked proteins could be more sensitizing because they are preferentially taken up by $\mathrm{M}$ cells and directly interact with immune cells in Peyer's patches. Roth-Walter and co-workers described that the intestinal transport of soluble $\beta$-lactoglobulin occurs through enterocytes, while the uptake of its aggregates is redirected to Peyer's patches (Roth-Walter et al., 2008). On the other hand, smaller intact proteins are transferred via goblet-associated passage (also called GAP) and that may be linked to processing by CD103 + DCs, facilitating tolerance rather than to other DCs that are linked to sensitization (McDole et al., 2012). M cell transfer and GAP are not often studied 
using in vitro methods, but cell lines as well as organoids can be adapted to study the particular involvement of these transportation routes. For instance, cell lines and intestinal stem cell-derived organoids can be stimulated to form M cells by RANKL-RANK pathway activation (Kimura, 2018) and GAP could be studied in specialized cell lines (HT29-H cells) or in organoids (constitutive presence of goblet cells).

Endocytosis is a complex process that includes caveolea-mediated uptake mechanisms, clathrin-dependent and -independent uptake mechanisms, macro-pinocytosis and phagocytosis. These processes may operate alongside each other and can be studied by using specific inhibitors (Dutta \& Donaldson, 2012). Important to mention here is that many of these inhibitors (e.g. filipin, cytochalasinD and monodansylcadaverine) also affect viability as well as TEER values (Price et al., 2017). Little information with regard to the importance of various mechanisms of endocytosis is yet available for food allergens. But studies with individual proteins show that different mechanisms of endocytosis may be involved for different proteins; for instance, Ara h 1 may be endocytosed via a combination of macro-pinocytosis and clathrin-dependent processes, whereas Ara h 2 may be endocytosed via a combination of macro-pinocytosis and caveolea-mediated uptake mechanisms (Price et al., 2017). Although authors speculate that the localization of Ara h 2 resulting from the specific way of endocytosis is linked to higher allergenicity of Ara h 2, other potential explanations such as their different molecular weight or physico-chemical properties should be also considered.

Altogether, in vitro models such as Caco- 2 cells cultured onto transwell systems seem suitable to study the importance of MIE2 and MIE3 in sensitization to food proteins. However, no data is currently available for ranges of allergens and clearly this information is needed to link endocytosis per se as well as the type of translocation to the sensitizing potential of a food protein.

\subsection{In vitro models to assess epithelium activation (KE1)}

Beyond being transported across the gut epithelial barrier, food proteins and their digestion products are able to interact with IECs in the intestinal lumen thereby triggering immune responses. It is widely accepted that food sensitization involves factors from gut epithelium, which are released after the activation of IECs (KE1). The presence of food allergens in the gut is mainly detected by pattern recognition receptors (PRRs), such as toll like receptors (TLRs), glycan binding receptors (galectins) or protease-activated receptors (PARs). This leads to the activation of inflammatory mechanism resulting in the activation of the NF- $\mathrm{kB}$ route and initiate the repair process for the damaged barrier with the production and secretion of chemokines, cytokines, reactive oxygen species (ROS), and lipid metabolites.

In vitro studies have closely linked the production of ROS to the activation of epithelial cells in the case of aeroallergens. The presence of IL-13 in the environment and the activation of PAR-2 receptor have been implicated in the upregulation of ROS production by epithelial cells (Dickinson et al., 2016; Nadeem et al., 2015). However, the effect of food allergens on IECs have not been so furtherly studied and we can only report the case of peanut allergens, in which an increase in the nitric oxide synthase gene expression has been observed (Starkl et al., 2011).

In response to their activation, IECs are also able to release epithelial-specific cytokines (e.g. IL-1, IL-18, IL-25, IL-33, and the thymic stromal lymphopoietin -TSLP-) that are crucial for the initiation of food protein sensitization. This cytokine environment induces the activation of DCs, type 2 innate lymphoid cells (ILC2), basophils, eosinophils, and mast cells, skewing the intestinal immune system towards a Th2 response. IL-33, IL-25, and TSLP are constitutively expressed by epithelial cells being IL-33 a crucial regulator of mast cells. Besides that, IL-33 is able to enhance granulocyte, macrophage, and ILC2 responses (Saluja, Khan, Church, \& Maurer, 2015). IL-25 elicits multipotent progenitor type 2 cells, a population of innate cells promoting type 2 cell immunity even in absence of ILC2 (Saenz et al., 2013). Regarding TSLP, its expression is increased in a NF- $\mathrm{kB}$ dependent-manner, being able to activate mast cells and influencing antibody production (Miron \& Cristea, 2012). On the other hand, the production of IEC-derived TGF- $\beta$ promotes DCs involved in tolerogenic signals, which is an important milestone for the control of allergic sensitization (Wang \& Sampson, 2009). Tordesillas et al. examined the effect of the major peach allergen Pru $\mathrm{p} 3$, in comparison with that of the hypoallergenic peach LTP 1 using Caco-2 cells grown in a transwell system. Authors showed that in the presence of Pru p 3 an increased expression of Th2-driving cytokines (IL-25, IL-33, and TSLP) was observed. However, with the hypoallergenic protein LTP 1 , the induction these cytokines was significantly lower (Tordesillas et al., 2013). In other study, the effect of the peanut allergen Ara h 2 on IECs showed upregulation of the inflammatory cytokines IL-1 $\beta$ and IL-8 (Starkl et al., 2011).

Concluding, the activation of epithelial cells is a heterogeneous process in which the cytokine environment is crucial, for this reason the effects of more food allergens on IECS should be described using other cell types than Caco- 2 cells. Despite the fact that the majority of studies are focused on the analysis of the cytokines expression, other pathways should be explored, such as mucus secretion or $\mathrm{Ca}^{2+}$-signalling pathway alterations.

\subsection{In vitro models to assess antigen uptake combined with epithelium activation (MIE and KE1)}

Approaches which combine the possibility to evaluate the contribution of allergens transport (MIE) to IEC activation and cytokine production (KE1) are important tools for studying the immunogenic properties of food proteins. The interaction of food allergens with the intestinal epithelium not only leads to the secretion of innate cytokines, but also the production of chemokines and other soluble factors such as alarmins (e.g. uric acid, ATP, HMGB1, and S100 proteins) that drive immune polarization by affecting DC function and the adaptive response (Gavrovic-Jankulovic \& Willemsen, 2015; van Bilsen et al., 2017). Furthermore, there is evidence that mediators released by peripheral blood mononuclear cells (PBMCs) and mast cells contribute to increase intestinal permeability which means that immunologic status can, by itself, affect IEC activation and the access of the allergen through epithelium (Tordesillas et al., 2013).

In this sense, several strategies have already been attempted with relative success. IEC lines grown in transwell systems (e.g. Caco-2, T84, or HCT-8) have been used to assess allergen uptake and subsequent epithelium activation by measuring cytokine production or changes in gene expression induced by allergens (Starkl et al., 2011; Tordesillas et al., 2013). In order to study the influence of intestinal soluble factors from immune cells on IECs, some in vitro strategies have used separate monocultures of IECs and immune cells and then supernatant from immune cells has been applied to IECs (Martos, Lopez-Exposito, Bencharitiwong, Berin, \& Nowak-Wegrzyn, 2011; Tordesillas et al., 2013; Yamashita, Yokoyama, Hashimoto, \& Mizuno, 2016) or vice versa. This strategy may contribute to a better comprehensive understanding of the in vivo cross-talk affecting KE1.

In addition, co-culture systems allowing cross-talk between structural cells (IECs) and effector immune cells (such as basophils) are being attempted to study whether a food allergen induces not only a direct epithelial activation, but also its consequences on the underlying immune cells, enabling to assess the immune cell responses through epithelial activation. An in vitro model based on the co-culture of Caco2 cells and rat basophilic leukaemia cells (RBLs) has been used for the study of immune activation upon Gal d 2 challenge at the apical side of the IECs (Thierry, Bernasconi, Mercenier, \& Corthesy, 2009). Although not performed, epithelial activation markers may be evaluated using this co-culture system.

More complex co-cultures combining mucoid IECs, non-mucoid IECs and B cell lines (Caco-2/HT29/Raji-B) have been suggested in the 
literature as systems to integrate allergen uptake with epithelial activation markers as well as with modulation by the immune cell signals (Araujo \& Sarmento, 2013). However, such an integrative system has not yet been used for the study of food allergens.

\section{Dendritic cells}

\subsection{In vitro models to assess dendritic cell activation and migration (KE2} and KE3)

As major antigen presenting cells, gut-associated DCs play a key role in immunological pathways associated to food protein sensitization process. Food proteins or their digestion products may induce activation of DCs (KE2) by C-type lectin receptor (CLRs) or other PRRs leading to a decrease in TLR-induced IL-12 production, as well as upregulation of OX40L, TIM-4, or both. In addition, DCs can be activated by IEC-derived IL-33 which also upregulates OX40L expression on DCs. After allergen uptake and activation, DCs migrate (KE3) to draining lymph nodes mediated by the expression of CCR2, CCR5 and CCR7 molecules. Other interesting surface markers to assess as indicators of antigen presentation are HLA-DR (MHC class II), CD86 (Katayama et al., 2013) and DC-SIGN binding by fluorescent-labeled food proteins (Kamalakannan, Chang, Grishina, Sampson, \& Masilamani, 2016).

Besides DC assays analyzing the presence of (binding to) surface molecules and cytokine expression, other methods have been described evaluating the differences in DC endocytosis by incubating murine bone marrow-derived DCs (BM-DCs) with FITC-labeled $\beta$-lactoglobulin and by in vitro endolysosomal degradation of the native and cross-linked forms of this allergen (Stojadinovic, Pieters, Smit, \& Velickovic, 2014). These data indicated differences that correlated with the sensitizing potential in vivo, suggesting that these additional parameters may be useful in vitro parameters to evaluate the sensitizing potential of food proteins. On this regard, BM-DCs have been applied to estimate the effect of thermal process on ovalbumin and showed that a glycation product of this allergen, pyrraline, induced higher uptake by DCs associated with the scavenger receptor class A (Heilmann et al., 2014).

Transcriptomic profiling of allergen-activated DCs is another approach to compare the DCs activating potency of food proteins. Comparison of various cell lines with human monocyte-derived DCs (moDCs) by gene profiling suggested that the MUTZ- 3 cell line resembles moDCs (Larsson, Lindstedt, \& Borrebaeck, 2006). A clone of this cell line has been recently used to assess and predict the sensitizing potential of proteins in respiratory allergy in the Genomic Allergen Rapid Detection (GARD) assay. In this assay, cellular responses induced by eight selected proteins were assessed using transcriptional profiling, flow cytometry and multiplex cytokine analysis. A total of 391 potential biomarkers were identified as a predictive signature and series of crossvalidations supported the effectiveness of this model. These results together with biological pathway analysis of the transcriptomic data indicate that the investigated cell system is able to capture relevant events linked to type I hypersensitization (Zeller et al., 2018). Although promising, the relevance of this model for food sensitization induction in general remains to be established.

Migration assays using BM-DCs (Rhee, Zhong, Reizis, Cheong, \& Veillette, 2014) or MUTZ-3 cells (Rees et al., 2011) have been described in transwell systems in which activated DCs are applied in the upper chamber, whereas an appropriate chemokine is added to the lower chamber. After incubation, migrated cells are harvested from the lower chamber and quantified (Rhee et al., 2014). However, these migration assays have never been proven useful in a food allergen specific context.

3.2. In vitro models to assess interactions between epithelial and dendritic cells (approaches integrating KE1, KE2 and KE3)

The IECs- and DCs-derived signals constitute an allergen-induced inflammatory microenvironment that triggers DCs maturation and migration. Test methods incorporating IECs and DCs have been developed in a variety of formats: co-cultures of DCs/IECs, three-dimensional (3D) models reconciling the complex and dynamic interactions that exist in vivo between the intestinal epithelium and the luminal side, and between the epithelium and the underlying immune system on the basolateral side (Bermudez-Brito, Plaza-Diaz, Fontana, MunozQuezada, \& Gil, 2013). These methods have been applied to investigate cellular and molecular mechanisms triggered by prebiotics and bacteria. However, the impact of allergens on these mechanisms has not yet been investigated extensively with these test models. Cultures of DCs supplemented with IEC-conditioned medium may also be considered as alternatives to co-cultures. This method has been applied in the case of prebiotics using human moDCs cultured with HT-29 conditioned medium (de Kivit et al., 2017).

Although several studies have used cultures of IECs or DCs to assess the sensitizing potential of food allergens, only the previously mentioned study from Tordesillas et al. investigated the influence of a food allergen on the function of co-cultured IECs/DCs. In that study, a transwell system with Caco-2 cells was set up, including PBMCs from healthy donors in the basolateral compartment. The addition of the Pru p 3 onto the apical chamber induced increased expression of IL-1 $\beta$, IL-6, IL-10 and TNF- $\alpha$ genes in PBMCs which was related to the high transport rate of intact Pru p 3 over the Caco-2 barrier (Tordesillas et al., 2013). These types of methods allow a further characterization of the sensitizing potential of allergens by including the role of cell-cell contact as well as soluble molecules taking into account the cellular interactions. However, several specific limitations may be encountered during the development of these methods, such as compatibility of cell types or cell media, complexity of the systems, donor variability when using primary human cells.

\section{4. $T$ and $B$ cell differentiation}

\subsection{In vitro models to assess murine Th2 cell priming (KE4)}

Allergens are thought to invoke an allergic response due to their ability to activate $\mathrm{T}$ cells through their specific cell receptors (TCRs). Besides this primary pathway, the interaction of co-stimulatory and coinhibitory receptors of T cells (CD28, CTLA-4, OX40L) with ligands on antigen presenting cells activates antigen unspecific signals that lead to the differentiation of $\mathrm{T}$ cells into a Th2 phenotype (van Bilsen et al., 2017).

Due to the low allergen-specific $\mathrm{T}$ cell in vivo frequency, re-stimulation of pre-sensitized cells ex vivo is the most widely used method to evaluate priming potential of common food allergens in mice. Most studies use splenocytes, mesenteric lymph node cells, or a combination of both, although lamina propria mononuclear cells (Sun et al., 2016) and isolated CD4 ${ }^{+}$T cells (Kanjarawi et al., 2011; Pochard et al., 2010) have also been evaluated. Cell suspensions are prepared from immunized mice and cultured with the antigen for 3-6 days, depending on the subsequent analyses. $\mathrm{T}$ cell proliferation, expression of specific cellular surface markers and/or cytokine secretion are mostly determined in these studies. $T$ cell proliferation is one of the most common ways to assess $\mathrm{T}$ cell activation upon ex vivo re-stimulation with the allergen. To this end, several methods such as labeling of cells with a fluorescent dye (Pochard et al., 2010; Sun et al., 2016), incorporate a radioactive nucleoside into new strands of chromosomal DNA during mitotic cell division (Freidl et al., 2017; Stojadinovic et al., 2014) or colorimetric assays for assessing cell metabolic activity (Sun, Liu, Wang, Liu, \& Feng, 2013; Wai, Leung, Leung, \& Chu, 2016) have been used.

Proliferation assays have been performed for $\beta$-lactoglobulin (Mizumachi, Tsuji, \& Kurisaki, 2008; Stojadinovic et al., 2014), ovalbumin (Castro et al., 2012; Sun et al., 2016), tropomyosin (Capobianco et al., 2008; Wai et al., 2016), Cyp c 1 from carp (Freidl et al., 2017), peanut (Pochard et al., 2010), cashew and walnut extract (Kulis, Pons, 
\& Burks, 2009), and soybean proteins (Sun et al., 2013), showing in all the cases a strong proliferative response of the cells. Expression of specific surface markers have been measured in sensitized mice after challenge with whey and ovalbumin, showing an increase in the percentage of both, activated Th1 and Th2 cells compare to control animals (Lozano-Ojalvo, Perez-Rodriguez, Pablos-Tanarro, Molina, \& LopezFandino, 2017; Vonk et al., 2017). However, when peanut extract was used there was no difference in the percentage of activated Th2 cells, and the percentage of activated Th1 cells was decreased (Vonk et al., 2017).

Levels of secreted cytokines are often evaluated by ELISA or flow cytometry in cell culture supernatants. This method has been used to evaluate several food allergens from cow's milk (Kanjarawi et al., 2011; Stojadinovic et al., 2014), peanut (Smit et al., 2015; Zhu et al., 2016), hen's egg (Pablos-Tanarro, Lopez-Exposito, Lozano-Ojalvo, LopezFandino, \& Molina, 2016; Sun et al., 2016), soybeans (Sun et al., 2013) and shrimp (Wai et al., 2016). Moreover, extracts from whey, hen's egg white, peanut, cashew, walnut and sesame seeds have also been evaluated using this method (Lozano-Ojalvo et al., 2017; Smit et al., 2015; Vonk et al., 2017). A high increased secretion of Th2 cytokines (IL-4, IL5, IL-13) has been observed in all the studies, whereas some discrepancies were observed between allergenic proteins in their potency to induce IFN- $\gamma$ (Stojadinovic et al., 2014; Vonk et al., 2017) and IL-10 (Vonk et al., 2017). A few studies have measured increased levels of IL17 (Lozano-Ojalvo et al., 2017; Rupa, Nakamura, Katayama, \& Mine, 2014), while in other limited number of studies IL-22 and TNF- $\alpha$ levels showed no differences compared to non-sensitized control cells (PablosTanarro et al., 2016; Zhu et al., 2016).

The assays described above, have provided efficacy to identify known allergens that drive allergic reactions in individuals and allergen modifications that ameliorate their allergenic potential, as well as to identify $\mathrm{T}$ cell epitopes of cross-reactivity with other allergens. However, they are not effective to identify the allergenic potential of new proteins that are responsible for stimulating the underlying Th2 responses, mainly due to the need to use cells from previously sensitized mice against the same allergen to perform the assay. Moreover, although evaluation of $\mathrm{T}$ cell activation through $\mathrm{T}$ cell proliferation assays is widely describe in the literature using different strategies, the use of indirect methods such as those that measure mitochondrial activity (e.g. MTT or WST assays) should be avoided because they reflect viable cell metabolism and not specifically cell proliferation, requiring additional confirmations.

\subsection{In vitro models to assess human Th2 cell priming (KE4)}

The activation and priming of naive T cells (KE4) for allergic food proteins in the draining lymph nodes results from the recognition of an epitope presented by Th2 driving DCs in the context of HLA (MHC-II). Most of the approaches for investigating KE4 using human samples are based on the ex vivo re-stimulation of PBMCs from allergic patients and the study of the allergen-specific induced proliferation and cytokine production (Flinterman et al., 2010; Tao et al., 2016; Tiemessen et al., 2004; Vocca et al., 2011). Indeed, stimulation of PBMCs from cow's milk allergic children with $\beta$-lactoglobulin was found to induce cell proliferation and increased IL-13 over IFN- $\gamma$ release compared to healthy or tolerant controls (Vocca et al., 2011). Also in PBMCs from peanut allergic patients, allergen-specific proliferation could be assessed by determining proliferation within the $\mathrm{CD} 25^{+} \mathrm{CD} 134+\mathrm{CD}^{+}$ $\mathrm{T}$ cell population after stimulation with raw peanut (Tao et al., 2016). However, in peanut allergic patients, ex vivo stimulation of PBMCs with peanut extract increased both IL-13 and IFN- $\gamma$ as well as TNF- $\alpha$ levels compared to PBMCs from healthy controls (Flinterman et al., 2010).

However, as pointed out in the previous section for KE4, the precursor frequency of allergen-specific T cells is very low in the peripheral blood of allergic patients. In this regard, the generation of $\mathrm{T}$ cell lines and $\mathrm{T}$ cell clones is an interesting alternative that lead to analyze Th2 cell activation (Flinterman et al., 2010; Tiemessen et al., 2004). Assays to study the functionality of these allergen-specific $\mathrm{T}$ cells make the use of allergen induced selection and cloning to improve the sensitivity of the assay. A mixture of $\beta$-lactoglobulin derived synthetic peptides were used to generate antigen-specific T cell lines and clones from PBMCs of cow's milk allergic patients (Sakaguchi et al., 2002). Limiting dilution clones were isolated and then used for epitope mapping. Results showed a sequence of 12 amino acids recognized by three out of six T cell clones from 5 different patients, which was associated with presentation via HLADRB1*0405 (Sakaguchi et al., 2002). Kondo et al. further studied intracellular cytokine expression in two of those clones, showing an increased production of IL-4 and IFN- $\gamma$ both in combination with IL-10 (Kondo et al., 2005). In this sense, cytokine release measurement may provide additional information concerning the type of immune response that is raised against these epitopes. Tiemessen et al. generated T cell clones using whole cow's milk proteins and compared the cytokine response in a group of cow's milk allergic infants with nonsymptomatic allergic patients and healthy donors (Tiemessen et al., 2004). Results showed that all different groups strikingly reacted to milk proteins, although cytokine production by allergic individuals was the highest for IL-4, IL-13, IFN- $\gamma$, and IL-10 (Tiemessen et al., 2004). However, only the symptomatic group revealed a negative or no correlation between IL-4/IFN- $\gamma$ and IL-10, while in the other two groups there was a positive correlation, showing the importance of IL-10 as a regulatory cytokine involved in tolerance induction. In addition, $\mathrm{T}$ cells from the symptomatic group had a high expression of the activation marker CD69 (Tiemessen et al., 2004). Beyond studying differences in T cell phenotype between patients and controls, $\mathrm{T}$ cell epitope disruption can also be studied using $\mathrm{T}$ cell lines as showed by the fact that $\beta$ lactoglobulin was able to induce a higher proliferation and cytokine secretion than its products of hydrolysis (Knipping et al., 2012). In short-term peanut-specific T cell lines generated from PBMCs of peanut allergic patients, Ara h 1, Ara h 3, and Ara h 6 were identified to induce the highest proliferation and secretion of IL-13, showing that these cell lines created using crude peanut extract can be useful for allergen identification (Flinterman et al., 2010). Furthermore, allergen-specific $\mathrm{T}$ cell clones from HLA diverse donors can be generated in order to evaluate the epitopes involved in $\mathrm{T}$ cell activating capacity in a certain HLA context (Prickett et al., 2011, 2013). This method has been used to identify 10 core epitopes of Ara h 1 and 5 core epitopes of Ara h 2 that could effectively induce $\mathrm{T}$ cell proliferation in a HLA-DQ and/or HLADR and/or HLA-DP restricted manner (Prickett et al., 2011, 2013). In the latter study, it was also showed that Ara h 2 peptides were able to enhance IL-4 and IL-5 secretion (ELISPOT) in PBMCs from peanut allergic donors (Prickett et al., 2011).

Based on an in silico predictions, Ramesh et al. evaluated the immunogenic potential of 36 Ara $\mathrm{h} 1$ derived peptides studying proliferation and cytokine production after ex vivo re-stimulation of PBMCs from peanut allergic patients with those peptides (Ramesh et al., 2016). Almost all the in silico selected peptides induced proliferation and predominantly a high IL-13 release when compared to IFN- $\gamma$ (Ramesh et al., 2016). This study indicates that PBMCs from allergic donors, combined with an appropriate in silico prediction, may yet be sufficient to identify allergenic epitopes of certain food proteins. In addition, MHC-peptide tetramers assays have been previously used to identify allergen-specific T cells in PBMCs. DeLong et al. cultured PBMCs from peanut allergic patients with Ara $\mathrm{h} 1$ peptides loaded on biotinylated HLA-DR proteins and intracellular cytokine expression was identified in tetramer labeled cells (Delong et al., 2011). Results showed that CCR4 expressing Ara $\mathrm{h} 1$ reactive $\mathrm{T}$ cells responded to different epitopes and produced mostly IL-4 beyond other cytokines (Delong et al., 2011).

In these types of assays, allergen-specific $\mathrm{T}$ cells can be identified by a highly upregulated Th2-prone culturing environment. They may not provide much information regarding the sensitizing potential of a given food protein, but merely indicate whether specific (or novel) food-derived proteins or peptides can be recognized by $\mathrm{T}$ cells and pose a 
potential risk. Moreover, these approaches are useful to identity novel food epitopes that are recognized by $\mathrm{T}$ cells.

\subsection{In vitro models to assess $D C$ activation/migration and $T$ cell priming (approaches integrating KE2, KE3 and KE4)}

After DC activation (KE2 and KE3), DCs migrate to the draining lymph nodes and drive $\mathrm{T}$ cell activation and differentiation (KE4). In vitro models to study antigen presentation and polarization of Th0 toward Th2 cells are usually based on co-culture approaches using DCs and primed $\mathrm{T}$ cells.

In methods based on murine cells, BM-DCs have been co-cultured with $\mathrm{CD}^{+} \mathrm{T}$ cells from mice sensitized to peanut (Pochard et al., 2010), whey (Stojadinovic et al., 2014) and a panel of purified food proteins (Smit, de Zeeuw-Brouwer, van Roest, de Jong, \& van Bilsen, 2016). In addition, $\mathrm{CD}^{+}{ }^{+} \mathrm{T}$ cells have also been obtained from TCR transgenic strains such as DO11.10 (Ilchmann et al., 2010) or OT-II mice (Rhee et al., 2014). These studies have showed that DCs increased the expression of activation/migration markers (MHC-II, CD80, and CD86) and the release of stimulatory cytokines such as IL-6 and IL-12 after re-stimulation with the allergen. Furthermore, activated DCs induce a high proliferation and a marked Th2 profile (enhanced production of IFN- $\gamma$, IL-4, IL-13, and IL- 5 determined by ELISA) in primed $\mathrm{CD}^{+} \mathrm{T}$ cells. Similar results were obtained when DCs were directly isolated from mesenteric lymph nodes and co-cultured with $\mathrm{CD}^{+} \mathrm{T}$ cells from DO11.10 mice (Blazquez \& Berin, 2008).

Among human in vitro models, DCs used for co-culture with T cells have been obtained from differentiated THP-1 cell line (Katayama et al., 2013) and allergen-pulsed monocyte-derived DCs (Gomez et al., 2012; Scott-Taylor, Axinia, \& Strobel, 2017). Allergens have been shown to activate DCs revealed by an enhanced expression of CD80, CD83, and CD86 (Gomez et al., 2012), production of inflammatory cytokines (IL12p70, IL-1 $\beta$, TNF- $\alpha$, and IL-10) and up-regulated expression of MARCH genes. For the study of the cross-talk with T cells, PBMCs from healthy donors (Tordesillas et al., 2013) or cashew allergic patients (Archila et al., 2016) have been previously used. In addition, T cell lines generated from cow's milk allergic children (Meulenbroek et al., 2014) and $\mathrm{CD}^{+}{ }^{+} \mathrm{T}$ cells directly isolated from patient allergic to peach (Gomez et al., 2012) and other food allergens (Scott-Taylor et al., 2017) have been previously used for co-cultures. Results have shown that, in presence of the food allergen, DCs induce T cell proliferation (observed by flow cytometry using carboxyfluorescein succinimidyl ester molecule -CFSE- or CD154 staining) in sensitized individuals compared to healthy donors. In addition, allergen-pulsed DCs trigger activation of T cells and increase the production of T cell-like cytokines such as IL-4, IL-13, and IFN- $\gamma$.

One of the strengths of human in vitro models is the use of T cells from allergic patients in an autologous setting, although it coincides with a downside, the limited number of cells that can be used (Lundberg et al., 2008). In addition, there are variations in the experimental protocols used for pulsed-DCs alone with the allergen of interest (Gomez et al., 2012; Scott-Taylor et al., 2017) or combined with maturation factors, such as TNF- $\alpha$, IL-1 $\beta$, or LPS (Ashjaei et al., 2015). These differences during maturation can affect expression of DC co-stimulatory and maturation markers and thus the subsequent proliferation of $\mathrm{T}$ cells and cytokine production, although most of the studies were able to induce an allergen-specific response. Despite differences between the in vitro models, co-cultures of DCs/T cells provide useful information about antigen presentation and polarization ability of DCs in presence of primed $\mathrm{CD} 4^{+} \mathrm{T}$ cells.

\subsection{In vitro models to assess B cell isotype switching (KE5)}

The mechanisms controlling the induction of class switch recombination and production of IgE by switched B cells have been studied extensively. In vitro, the production of IgE by human B cells, specifically induced by IL-4 or IL-13 and signalling via CD40 cell surface molecule, can be monitored at various levels of the $\varepsilon$ class switching process, including during the induction of the sterile $\varepsilon$ transcript, which precedes Ig heavy chain locus rearrangement by quantitative reverse transcription PCR (RT-qPCR) or Northern blot assay, the detection of production of $\varepsilon$ excision circles during the Ig heavy chain locus rearrangement by PCR and the detection of production of IgE by ELISA as nicely reviewed by Pène et al., 2005.

Even though several in vitro B cell activation protocols are available (Lin \& Calame, 2004; Pène et al., 2005), to the best of our knowledge no protocols have been established so far that investigate the (various levels of) class switching in a food allergen-specific context.

\section{Future perspective}

\subsection{In vitro micro-fluidics systems}

Advances in micro-physiological systems are providing researchers alternative means to gain insights into the molecular interactions of the gastrointestinal tract. These systems combine the benefits of microengineering, micro-fluidics, and cell culture in a bid to recreate the environmental conditions prevalent in the human gut. It becomes now possible to construct in vitro systems that more closely approximate those conditions present within the gut on scales identical to those encountered in vivo (Kim, Huh, Hamilton, \& Ingber, 2012). These systems based on micro-fluidics offer numerous advantages over traditional cell-culturing techniques, including a 3D culture environment, greater experimental flexibility, the ability to precisely tune spatiotemporal oxygen and $\mathrm{pH}$ gradients, low shear environments, and the ability for high throughput experimentation. Although currently available micro-fluidics systems provide promising approaches to study local mechanisms that drive allergic responses, they have not yet been used to study any of the MIE or KE including in the AOP for food sensitization. Some examples of available micro-fluid devices are described below.

\subsubsection{Human gut-on-a-chip device}

A micro device "human gut-on-a-chip" has been developed by the Ingber group at Harvard University, which is composed of two microfluidic channels, separated by a porous flexible membrane coated with extracellular matrix and lined by Caco- 2 cells to mimics the complex structure and physiology of living intestine. The gut micro-environment is established by flowing fluid, which produces low shear stress over the micro-channels and exerts cyclic strain that mimics physiological peristaltic motions (Kim et al., 2012).

\subsubsection{NutriChip}

NutriChip is another integrated micro-fluidic platform developed by Swiss scientists for investigating potential immunomodulatory function of dairy food and represents a miniaturized artificial human gastrointestinal tract (Ramadan et al., 2013). NutriChip is a culture of a confluent layer of Caco-2 cells separated from co-cultured immune cells by a permeable membrane, which allows studying processes that characterize the passage of nutrients though the intestinal epithelium, including the activation of immune cells. NutriChip allows application of in vitro digested food on its apical side and a basolateral culture of a monocyte line (U937 cells) differentiated into macrophages (Ramadan et al., 2013).

\subsubsection{Immuno-HuMiX}

Human-microbial cross-talk platform (HuMiX) is also a micro-fluid device that enables the study of molecular interactions at the host-microbe interface (Eain et al., 2017). The features of HuMiX are similar to those of the other fluidics systems in which also the microbiome component may be introduced. Moreover, the system can be expanded to analyze the interactions between the immune system and the intestinal 


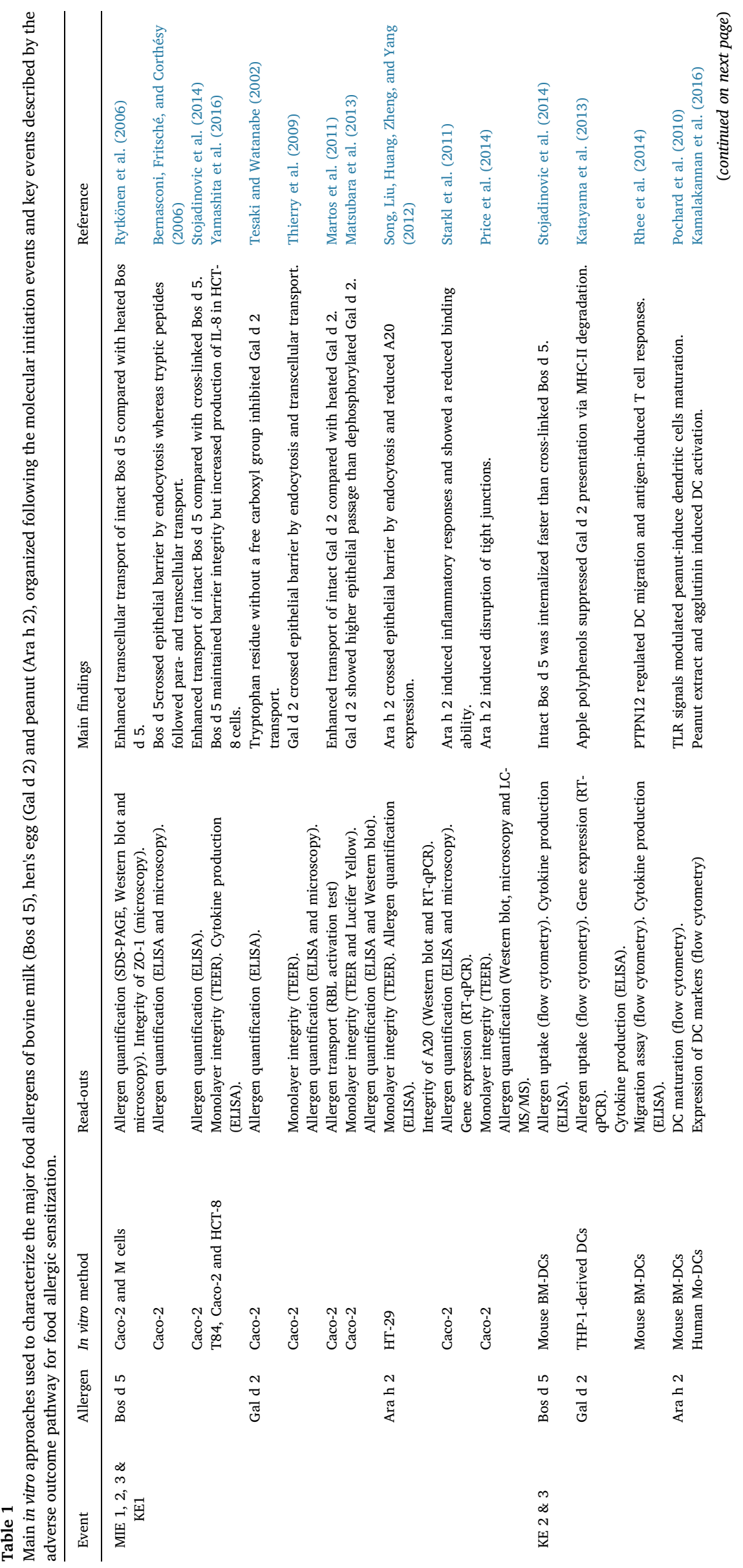




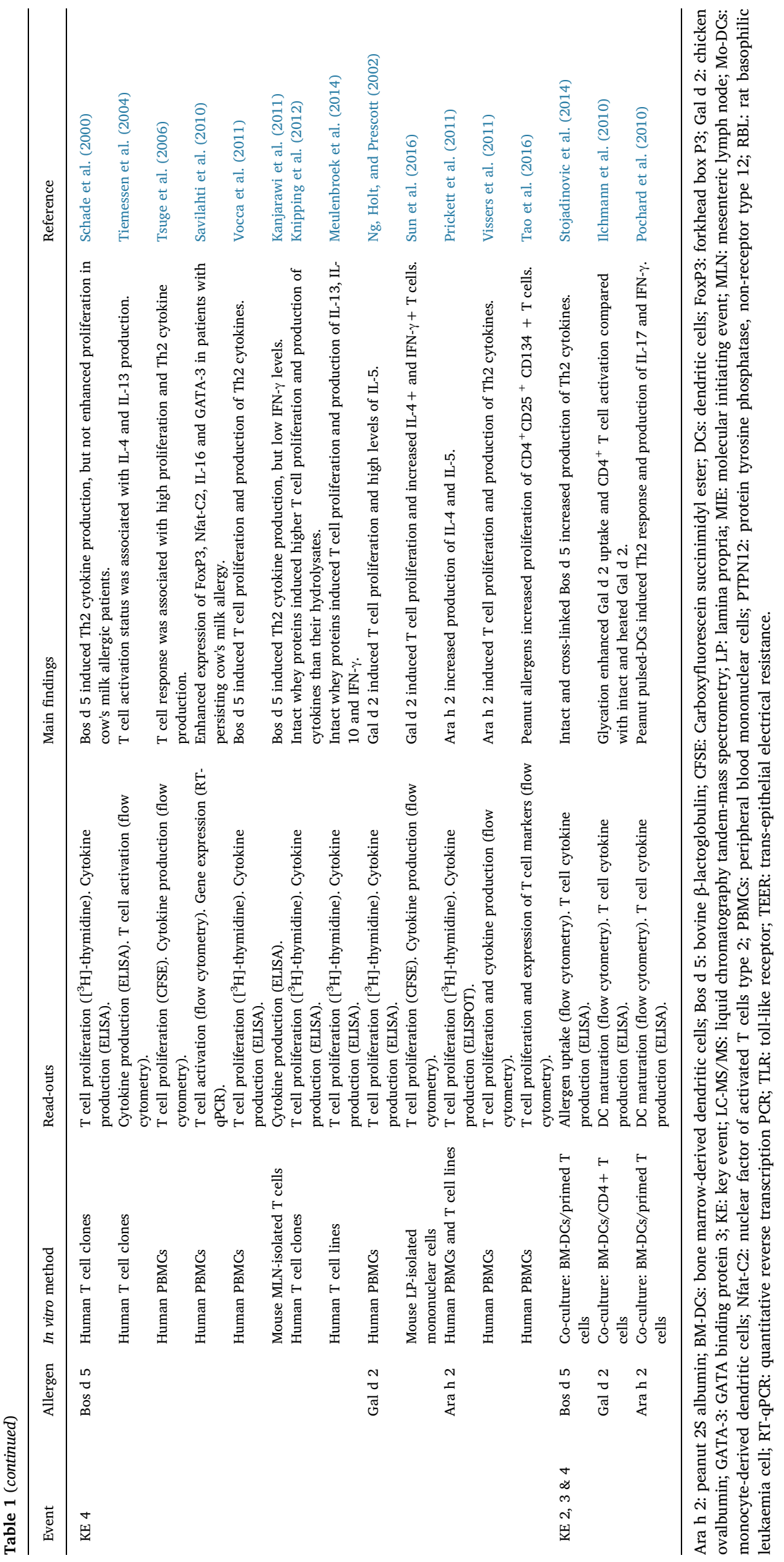


microbiota in the human gut, the so called Immuno-HuMix model. First steps have been undertaken to integrate human PBMCs in this system (Eain et al., 2017).

\subsection{Organotypic ex vivo cultures}

One of the major weaknesses of IEC lines is that they are different from the primary cells of the intestinal epithelium, from which they had originally been isolated. The selection of cells that survive and expand in vitro often leads to changes in gene expression profile and altered responses. In this respect, primary isolated cells may therefore be a better model system to represent processes in the intestinal mucosa. Promising ex vivo approaches are the generation of intestinal organoids and the culturing of ex vivo intestine samples.

\subsubsection{Intestinal organoids}

Major advances have been made in establishing culture conditions that support the long-term propagation and self-organisation of nearphysiological tissue. In general, isolated somatic stem cells from various organs are cultured in the presence of specific small molecules and growth factors, reflecting essential niche components of the respective tissue of origin. A 3D scaffold mimicking the basal lamina has further been shown to support ex vivo expansion of intestinal stem cells ex vivo and tissue formation that resembles part of the cellular architecture, hierarchy and physiology of the in vivo counterpart (Sato \& Clevers, 2013). The culture of intestinal crypts and their growth and differentiation to organoids may be an interesting and easy to handle tool to study allergen interaction and associated signal transduction pathways in a complex intestinal system.

Despite the requirement for more expensive technology than IEC lines, intestinal organoids have been shown to have multiple applications and with the recent development of efficient gene-editing tools, it is now possible to generate highly physiological models of human gastrointestinal diseases (Leushacke \& Barker, 2014). However, the study of allergen transport across the epithelial barrier is limited by the inaccessibility of food proteins to the apical side of IECs (directed to the lumen of the organoids).

\subsubsection{Ex vivo models}

Another approach to overcome the major drawbacks of the in vitro cell line-based models may be the use of complete intestinal tissues. In these models, the asymmetrical distribution of proteins and lipids in the two plasma membrane domains is facing the intestinal lumen. The internal milieu and the presence of highly organized structures joining adjacent IECs, enable selective processes of absorption, transport, and secretion to take place across the intestinal mucosa. The main ex vivo intestinal models for intestinal protein transport studies include the everted sac technique and the Using chamber. These approaches have been largely used to assess protein transport and, using intestinal tissue from sensitized animals, they may lead to study the effect of sensitization on allergen uptake. However, both techniques have several limitations including the rapid loss of the tissue viability and tissue damages during isolation, which may lead to overestimation of protein transport. Furthermore, the presence of the muscle layer in the everted sac method may lead to underestimation of protein transport. On the other hand, interspecies differences complicate extrapolation of data to humans. In this respect, pigs share more physiological and immunological similarities with humans than rodents and the recently developed InTESTine ${ }^{\mathrm{TM}}$ method may be a medium-throughput alternative. InTESTine ${ }^{\mathrm{TM}}$ is based on intestinal tissues from pigs that are incubated on a rocker platform in a high oxygen incubator (Westerhout et al., 2014).

\subsection{In silico approaches}

In silico methodologies and tools like databases and comparison software have been shown useful for the assessment of potential allergenicity of food proteins based on their properties. These in silico methods use a number of physico-chemical features (mainly amino acid searches) of proteins that can be predicted, such as B cell epitopes, $\mathrm{T}$ cell epitopes and sequence homologies (as reviewed by Hayes, Rougé, Barre, Herouet-Guicheney, \& Roggen, 2015). They can identify whether a novel protein is an existing allergen and/or has the potential to crossreact with an existing allergen. However, they cannot identify whether a novel protein will 'become' an allergen, so therefore these approaches have limited value to identify truly novel allergenic proteins (Hayes et al., 2015). The use of future innovative in silico approaches will be largely influenced by the choice of databases and algorithms that will be developed, standardized, and most importantly, empirically validated.

\section{Conclusion}

Although basic science studies have identified a lot of immune pathways behind the allergic response, sensitization to food proteins is a complex process involving several molecular and cellular events (Sicherer \& Sampson, 2018; Tordesillas, Berin, \& Sampson, 2017). The simplification of the biological process of food allergy sensitization by applying the AOP concept is an effective strategy to identify in vitro methods that lead to investigate the sensitizing potential of food proteins. Previously, such an approach focusing on MIE and KE described in reported AOPs for skin and respiratory sensitization have been used successfully to study the sensitizing potential chemicals in skin and respiratory allergy (Ezendam, Braakhuis, \& Vandebriel, 2016; Sullivan et al., 2017).

In this review, we have clustered, structured, and discussed the existing in vitro models that are suitable to study the MIE and KE involved in the AOP for food allergy sensitization (van Bilsen et al., 2017). To the best of our knowledge, this is the first time that the AOP concept is applied to structure all available in vitro methods to identify the potential sensitizing capacity of food proteins. In order to recapitulate all the reviewed assays, focusing on different (combinations of) MIE and KE reflecting the different building blocks of the AOP, Table 1 summarized in vitro methods used to evaluate the three major food allergens: chicken ovalbumin ( $\mathrm{Gal} \mathrm{d} \mathrm{2),} \mathrm{bovine} \beta$-lactoglobulin (Bos d 5) and peanut 2S albumin (Ara h 2).

In general, in vitro methods assessing mechanisms involved in the innate immune response are easier to address than assays assessing the adaptive immune response of food sensitization: the recognition molecules used by the innate system (here reflected in MIE, KE1, KE2, and KE3), are expressed broadly on a large number of cells, which makes it easier to develop in vitro methodologies to study specific building blocks of the AOP, as seen by the rich set of available tools. However, more in vitro studies of the transcellular transport based on epithelial receptors (MIE2) or unspecific endocytosis (MIE3) should be carried out to better understand the effect of this type of intestinal acquisition in the sensitizing potential of food proteins.

On the other hand, the adaptive immune system (here reflected in KE4 and KE5) is composed of small numbers of T and B cells with specificity of any individual allergen. Therefore the responding cells must proliferate after encountering the allergen in order to attain sufficient numbers to mount an effective response that can be detected. This feature of the adaptive system complicates the development of in vitro approaches to assess KE4 and KE5. This is also reflected in Table 1 which depicts a limited number of in vitro approaches to address KE4 and the absence of an available in vitro assay to assess B cell isotype switching (KE5) in a food-allergen specific context.

It must be noted that the in vitro models discussed in this manuscript have been developed to obtain a better understanding of the processes involved in food sensitization. Several of the described in vitro models (summarized in Table 1) seem to be correlated with the sensitizing potential in vivo and some show great promise to closely approximate in 
vivo conditions (e.g. in vitro micro-fluidics systems and organotypic cultures), however as far as we know, none of the described models have been successfully used to assess the sensitizing potential of a given food protein by comparing high and low/none sensitizing food proteins in the assay. To this end, it would be an essential step forward to expand the panel of tested food proteins by including also low/non-allergenic proteins. Most likely, none of the assays will be able to distinguish high from low/non allergenic potency by itself; however the assays combined can provide an important set of data which may be helpful to decide which of the assays are essential to be part of the weight-of-evidence approach to determine the sensitizing potential of food proteins. Unfortunately, to date it is not known whether the lack of a suitable in vitro model to assess KE5 (B cell isotype switching) will result in a crucial data gap to determine the sensitizing potential or whether the KE5-model is redundant in the overall assessment.

In vitro models based on cell lines are very useful as research tools to investigate MIE and KE involved in food allergy sensitization. However, the closer these cell-based systems are to the actual target tissue, the better conclusions can be drawn. The main problem was that long-term propagation of native, non-transformed single cells or cell clusters from the intestine was not feasible and it was generally assumed that it would not be possible to establish long-term cultures of primary adult tissues without the introduction of genetic transformations promoting cell proliferation and survival. In recent years, significant progress has been made in this field and robust systems have been identified. A variety of in vitro micro-fluidics systems and ex vivo culture strategies has been developed to investigate the function of the intestinal mucosa, which will help to increase the knowledge of food sensitization process.

Concluding, the application of the AOP framework offers the opportunity to anchor existing testing methods to specific building blocks of the AOP for food sensitization which provides insight which specific methods are available and which still need to be developed. When applied in the context of an integrated testing strategy, such an approach may reduce, if not replace, current animal testing approaches.

\section{Acknowledgments}

The authors are all part of the COST Action FA1402 entitled: Improving Allergy Risk Assessment Strategy for New Food Proteins (ImpARAS). We highly appreciate the support and suggestions of Prof. Dr. Djuro Josic. This research did not receive any specific grant from funding agencies in the public, commercial, or not-for-profit sectors.

\section{References}

Araujo, F., \& Sarmento, B. (2013). Towards the characterization of an in vitro triple coculture intestine cell model for permeability studies. International Journal of Pharmaceutics, 458(1), 128-134. https://doi.org/10.1016/j.ijpharm.2013.10.003.

Archila, L. D., Chow, I. T., McGinty, J. W., Renand, A., Jeong, D., Robinson, D., ... Kwok, W. W. (2016). Ana o 1 and Ana o 2 cashew allergens share cross-reactive CD4(+) T cell epitopes with other tree nuts. Clinical and Experimental Allergy, 46(6), 871-883. https://doi.org/10.1111/cea.12746.

Ashjaei, K., Bublin, M., Smole, U., Lengger, N., Hafner, C., Breiteneder, H., ... HoffmannSommergruber, K. (2015). Differential T-helper cell polarization after allergen-specific stimulation of autologous dendritic cells in polysensitized allergic patients. International Archives of Allergy and Immunology, 166(2), 97-106. https://doi.org/10. 1159/000375405.

Bermudez-Brito, M., Plaza-Diaz, J., Fontana, L., Munoz-Quezada, S., \& Gil, A. (2013). In vitro cell and tissue models for studying host-microbe interactions: A review. British Journal of Nutrition, 109, S27-S34. https://doi.org/10.1017/s0007114512004023.

Bernasconi, E., Fritsché, R., \& Corthésy, B. (2006). Specific effects of denaturation, hydrolysis and exposure to Lactococcus lactis on bovine $\beta$-lactoglobulin transepithelial transport, antigenicity and allergenicity. Clinical and Experimental Allergy, 36(6), 803-814. https://doi.org/10.1111/j.1365-2222.2006.02504.x.

van Bilsen, J. H. M., Sienkiewicz-Szlapka, E., Lozano-Ojalvo, D., Willemsen, L. E. M., Antunes, C. M., Molina, E., ... Roggen, E. L. (2017). Application of the adverse outcome pathway (AOP) concept to structure the available in vivo and in vitro mechanistic data for allergic sensitization to food proteins. Clinical and Translational Allergy, 7, 18. https://doi.org/10.1186/s13601-017-0152-0.

Bischoff, S. C., \& Kramer, S. (2007). Human mast cells, bacteria, and intestinal immunity. Immunological Reviews, 217, 329-337. https://doi.org/10.1111/j.1600-065X.2007. 00523.x.
Blazquez, A. B., \& Berin, M. C. (2008). Gastrointestinal dendritic cells promote Th2 skewing via OX40L. The Journal of Immunology, 180(7), 4441-4450. https://doi.org/ 10.4049/jimmunol.180.7.4441.

Bodinier, M., Legoux, M. A., Pineau, F., Triballeau, S., Segain, J. P., Brossard, C., et al. (2007). Intestinal translocation capabilities of wheat allergens using the caco-2 cell line. Journal of Agricultural and Food Chemistry, 55(11), 4576-4583. https://doi.org/ 10.1021/jf070187e.

de Boer, A., \& Bast, A. (2018). Demanding safe foods - safety testing under the novel food regulation (2015/2283). Trends in Food Science \& Technology, 72, 125-133. https:// doi.org/10.1016/j.tifs.2017.12.013.

Boyce, J. A., Assa, A., Burks, A. W., Jones, S. M., \& Hugh, A. (2010). Guidelines for the diagnosis and management of food allergy in the United States: Report of the NIAIDsponsored expert panel. The Journal of Allergy and Clinical Immunology, 126(60), S1-S58. https://doi.org/10.1016/j.jaci.2010.10.007.

Capobianco, F., Butteroni, C., Barletta, B., Corinti, S., Afferni, C., Tinghino, R., ... Di Felice, G. (2008). Oral sensitization with shrimp tropomyosin induces in mice allergen-specific IgE, T cell response and systemic anaphylactic reactions. International Immunology, 20(8), 1077-1086. https://doi.org/10.1093/intimm/dxn065.

Castro, M. S., Azpiroz, M. B., Molina, M. A., Mourelle, A. C., Alaniz, F. S., Maldonado, A. M., et al. (2012). Preliminary studies on the prevention of the ovalbumin-induced allergic response by Enterococcus faecalis CECT7121 in mice. International Archives of Allergy and Immunology, 157(1), 11-20. https://doi.org/10.1159/000324673.

Ceponis, P. J. M., Botelho, F., Richards, C. D., \& McKay, D. M. (2000). Interleukins 4 and 13 increase intestinal epithelial permeability by a phosphatidylinositol 3-kinase pathway - lack of evidence for STAT 6 involvement. Journal of Biological Chemistry, 275(37), 29132-29137. https://doi.org/10.1074/jbc.M003516200.

Cubells-Baeza, N., Verhoeckx, K. C. M., Larre, C., Denery-Papini, S., Gavrovic-Jankulovic, M., \& Diaz Perales, A. (2015). Applicability of epithelial models in protein permeability/transport studies and food allergy. Drug Discovery Today: Disease Models, 17-18, 13-21. https://doi.org/https://doi.org/10.1016/j.ddmod.2016.08.002.

Delong, J. H., Simpson, K. H., Wambre, E., James, E. A., Robinson, D., \& Kwok, W. W. (2011). Ara h 1-reactive T cells in individuals with peanut allergy. The Journal of Allergy and Clinical Immunology, 127(5), 1211-1218. e3 https://doi.org/10.1016/j. jaci.2011.02.028.

Dickinson, J. D., Alevy, Y., Malvin, N. P., Patel, K. K., Gunsten, S. P., Holtzman, M. J., ... Brody, S. L. (2016). IL13 activates autophagy to regulate secretion in airway epithelial cells. Autophagy, 12(2), 397-409. https://doi.org/10.1080/15548627.2015. 1056967.

Dutta, D., \& Donaldson, J. G. (2012). Search for inhibitors of endocytosis. Cellular Logistics, 2(4), 203-208. https://doi.org/10.4161/cl.23967.

Eain, M. M. G., Baginska, J., Greenhalgh, K., Fritz, J. V., Zenhausern, F., \& Wilmes, P. (2017). Engineering solutions for representative models of the gastrointestinal human-microbe interface. Engineering, 3(1), 60-65. https://doi.org/10.1016/j.Eng. 2017.01.011.

Eigenmann, P. A., Beyer, K., Wesley Burks, A., Lack, G., Liacouras, C. A., Hourihane, J. O B., ... Sodergren, E. (2008). New visions for food allergy: An iPAC summary and future trends. Pediatric Allergy \& Immunology, (Suppl 19), 26-39. https://doi.org/10. 1111/j.1399-3038.2008.00765.x.

Ezendam, J., Braakhuis, H. M., \& Vandebriel, R. J. (2016). State of the art in non-animal approaches for skin sensitization testing: From individual test methods towards testing strategies. Archives of Toxicology, 90(12), 2861-2883. https://doi.org/10. 1007/s00204-016-1842-4.

Flinterman, A. E., Pasmans, S. G. M. A., Den Hartog Jager, C. F., Hoekstra, M. O., Bruijnzeel-Koomen, C. A. F. M., Knol, E. F., et al. (2010). T cell responses to major peanut allergens in children with and without peanut allergy. Clinical and Experimental Allergy, 40(4), 590-597. https://doi.org/10.1111/j.1365-2222.2009. 03431.x.

Freidl, R., Gstoettner, A., Baranyi, U., Swoboda, I., Stolz, F., Focke-Tejkl, M., ... Linhart, B. (2017). Blocking antibodies induced by immunization with a hypoallergenic parvalbumin mutant reduce allergic symptoms in a mouse model of fish allergy. The Journal of Allergy and Clinical Immunology, 139(6), 1897-1905. https://doi.org/10. 1016/j.jaci.2016.10.018.

Gavrovic-Jankulovic, L., \& Willemsen, L. E. M. (2015). Pithelial models to study food allergen-induced barrier disruption and immune activation. Drug Discovery Today: Disease Models, 17-18, 29-36. https://doi.org/https://doi.org/10.1016/J.DDMOD 2016.09.002.

Gomez, E., Diaz-Perales, A., Tordesillas, L., Dona, I., Torres, M. J., Blazquez, A. B., ... Mayorga, C. (2012). Effect of Pru p 3 on dendritic cell maturation and T-lymphocyte proliferation in peach allergic patients. Annals of Allergy, Asthma, \& Immunology, 109(1), 52-58. https://doi.org/10.1016/j.anai.2012.05.017.

Grootaert, C., Jacobs, G., Matthijs, B., Pitart, J., Baggerman, G., Possemiers, S., ... Voorspoels, S. (2017). Quantification of egg ovalbumin hydrolysate-derived antihypertensive peptides in an in vitro model combining luminal digestion with intestinal Caco-2 cell transport. Food Research International, 99, 531-541. https://doi. org/10.1016/j.foodres.2017.06.002.

Grozdanovic, M. M., Cavic, M., Nesic, A., Andjelkovic, U., Akbari, P., Smit, J. J., et al (2016). Kiwifruit cysteine protease actinidin compromises the intestinal barrier by disrupting tight junctions. Biochimica et Biophysica Acta (BBA) - General Subjects, 1860(3), 516-526. https://doi.org/10.1016/j.bbagen.2015.12.005.

Hayes, M., Rougé, P., Barre, A., Herouet-Guicheney, C., \& Roggen, E. L. (2015). In silico tools for exploring potential human allergy to proteins. Drug Discovery Today: Disease Models, 17-18, 3-11. https://doi.org/10.1016/j.ddmod.2016.06.001.

Heilmann, M., Wellner, A., Gadermaier, G., Ilchmann, A., Briza, P., Krause, M., ... Toda, M. (2014). Ovalbumin modified with pyrraline, a maillard reaction product, shows enhanced T-cell immunogenicity. Journal of Biological Chemistry, 289(11), 7919-7928. https://doi.org/10.1074/jbc.M113.523621. 
Ilchmann, A., Burgdorf, S., Scheurer, S., Waibler, Z., Nagai, R., Wellner, A., ... Toda, M. (2010). Glycation of a food allergen by the Maillard reaction enhances its T-cell immunogenicity: Role of macrophage scavenger receptor class A type I and II. The Journal of Allergy and Clinical Immunology, 125(1), 175-183. https://doi.org/10. 1016/j.jaci.2009.08.013.

Kamalakannan, M., Chang, L. M., Grishina, G., Sampson, H. A., \& Masilamani, M. (2016). Identification and characterization of DC-SIGN-binding glycoproteins in allergenic foods. Allergy: European Journal of Allergy and Clinical Immunology, 71(8), 1145-1155. https://doi.org/10.1111/all.12873.

Kanjarawi, R., Dercamp, C., Etchart, N., Adel-Patient, K., Nicolas, J. F., Dubois, B., et al. (2011). Regulatory T cells control type I food allergy to beta-lactoglobulin in mice. International Archives of Allergy and Immunology, 156(4), 387-396. https://doi.org/ 10.1159/000323940.

Katayama, S., Kukita, T., Ishikawa, E., Nakashima, S., Masuda, S., Kanda, T., ... Nakamura, S. (2013). Apple polyphenols suppress antigen presentation of ovalbumin by THP-1-derived dendritic cells. Food Chemistry, 138(2-3), 757-761. https://doi. org/10.1016/j.foodchem.2012.10.076.

Kim, H. J., Huh, D., Hamilton, G., \& Ingber, D. E. (2012). Human gut-on-a-chip inhabited by microbial flora that experiences intestinal peristalsis-like motions and flow. Lab on a Chip, 12(12), 2165-2174. https://doi.org/10.1039/c2lc40074j.

Kimura, S. (2018). Molecular insights into the mechanisms of M-cell differentiation and transcytosis in the mucosa-associated lymphoid tissues. Anatomical Science International, 93(1), 23-34. https://doi.org/10.1007/s12565-017-0418-6.

de Kivit, S., Kostadinova, A. I., Kerperien, J., Muruzabal, V. A., Morgan, M. E., Knippels, L. M. J., ... Willemsen, L. E. M. (2017). Galectin-9 produced by intestinal epithelial cells enhances aldehyde dehydrogenase activity in dendritic cells in a PI3K-and p38-dependent manner. Journal of Innate Immunity, 9(6), 609-620. https://doi.org/10. 1159/000479817.

Knipping, K., Van Esch, B. C. A. M., Van Ieperen-Van Dijk, A. G., Van Hoffen, E., Van Baalen, T., Knippels, L. M. J., ... Knol, E. F. (2012). Enzymatic treatment of whey proteins in Cow's milk results in differential inhibition of IgE-mediated mast cell activation compared to T-cell activation. International Archives of Allergy and Immunology, 159(3), 263-270. https://doi.org/10.1159/000338007.

Kondo, M., Suzuki, K., Inoue, R., Sakaguchi, H., Matsukuma, E., Kato, Z., ... Kondo, N. (2005). Characterization of T-cell clones specific to Ovomucoid from patients with egg-white allergy. Journal of Investigational Allergology and Clinical Immunology, 15(2), $107-111$.

Kulis, M., Pons, L., \& Burks, A. W. (2009). In vivo and T cell cross-reactivity between walnut, cashew and peanut. International Archives of Allergy and Immunology, 148(2), 109-117. https://doi.org/10.1159/000155741.

Larsson, K., Lindstedt, M., \& Borrebaeck, C. A. K. (2006). Functional and transcriptional profiling of MUTZ-3, a myeloid cell line acting as a model for dendritic cells. Immunology, 117(2), 156-166. https://doi.org/10.1111/j.1365-2567.2005.02274.x.

Lebreton, C., Ménard, S., Abed, J., Moura, I. C., Coppo, R., Dugave, C., ... Heyman, M. (2012). Interactions among secretory immunoglobulin A, CD71, and transglutaminase-2 affect permeability of intestinal epithelial cells to gliadin peptides. Gastroenterology, 143(3), 698-707. https://doi.org/10.1053/j.gastro.2012.05.051.

Leushacke, M., \& Barker, N. (2014). Ex vivo culture of the intestinal epithelium: Strategies and applications. Gut, 63(8), 1345-1354. https://doi.org/10.1136/gutjnl-2014. 307204.

Li, H., Chehade, M., Liu, W., Xiong, H., Mayer, L., \& Berin, M. C. (2007). Allergen-IgE complexes trigger CD23-dependent CCL20 release from human intestinal epithelial cells. Gastroenterology, 133(6), 1905-1915. https://doi.org/10.1053/j.gastro.2007. 09.024.

Lin, K. I., \& Calame, K. (2004). Introduction of genes into primary murine splenic B cells using retrovirus vectors. In H. Gu, \& K. Rajewsky (Eds.). Methods mol biol (pp. 139148). Humana Press. https://doi.org/10.1385/1-59259-796-3:139.

Lozano-Ojalvo, D., Perez-Rodriguez, L., Pablos-Tanarro, A., Molina, E., \& Lopez-Fandino, R. (2017). Hydrolysed ovalbumin offers more effective preventive and therapeutic protection against egg allergy than the intact protein. Clinical and Experimental Allergy, 47(10), 1342-1354. https://doi.org/10.1111/cea.12989.

Lundberg, K., Lindsted, M., Larsson, K., Dexlin, L., Wingren, C., Ohlin, M., ... Borrebaeck, C. A. K. (2008). Augmented Phl p 5-specific Th2 response after exposure of dendritic cells to allergen in complex with specific IgE compared to IgG1 and IgG4. Clinical Immunology, 128(3), 358-365. https://doi.org/10.1016/j.clim.2008.04.011.

Martos, G., Lopez-Exposito, I., Bencharitiwong, R., Berin, M. C., \& Nowak-Wegrzyn, A. (2011). Mechanisms underlying differential food allergy response to heated egg. The Journal of Allergy and Clinical Immunology, 127(4), 990-997. https://doi.org/10. 1016/j.jaci.2011.01.057.

Matsubara, T., Akiyama, Y., Oshima, K., Okajima, T., Nadano, D., \& Matsuda, T. (2013). Dephosphorylation reduces passage of ovalbumin antigen through intestinal epithelial Caco-2 cell monolayers. Journal of Biochemistry, 154(4), 347-354. https://doi. org/10.1093/jb/mvs154.

Mazzucchelli, G., Holzhauser, T., Cirkovic Velickovic, T., Diaz-Perales, A., Molina, E., Roncada, P., ... Hoffmann-Sommergruber, K. (2018). Current (food) allergenic risk assessment: Is it fit for novel foods? Status Quo and identification of gaps. Molecular Nutrition \& Food Research, 62(1), 1700278. https://doi.org/10.1002/mnfr. 201700278.

McClain, S., Bowman, C., Fernández-Rivas, M., Ladics, G. S., \& Van Ree, R. (2014). Allergic sensitization: Food- and protein-related factors. Clinical and Translational Allergy, 4, 11. https://doi.org/10.1186/2045-7022-4-11.

McDole, J. R., Wheeler, L. W., McDonald, K. G., Wang, B., Konjufca, V., Knoop, K. A., .. Miller, M. J. (2012). Goblet cells deliver luminal antigen to CD103 + dendritic cells in the small intestine. Nature, 483, 345-349. https://doi.org/10.1038/nature10863.

Meulenbroek, L., Oliveira, S., Jager, C. F. D., Klemans, R. J. B., Lebens, A. F. M., van Baalen, T., ... van Hoffen, E. (2014). The degree of whey hydrolysis does not uniformly affect in vitro basophil and T cell responses of cow's milk-allergic patients. Clinical and Experimental Allergy, 44(4), 529-539. https://doi.org/10.1111/cea. 12254.

Miron, N., \& Cristea, V. (2012). Enterocytes: Active cells in tolerance to food and microbial antigens in the gut. Clinical and Experimental Immunology, 167(3), 405-412. https://doi.org/10.1111/j.1365-2249.2011.04523.x.

Mizumachi, K., Tsuji, N. M., \& Kurisaki, J. I. (2008). Suppression of immune responses to beta-lactoglobulin in mice by the oral administration of peptides representing dominant T cell epitopes. Journal of the Science of Food and Agriculture, 88(3), 542-549. https://doi.org/10.1002/jsfa.3122.

Moreno, F. J., Rubio, L. A., Olano, A., \& Clemente, A. (2006). Uptake of $2 S$ albumin allergens, Ber e 1 and Ses i 1, across human intestinal epithelial Caco-2 cell monolayers. Journal of Agricultural and Food Chemistry, 54(22), 8631-8639. https://doi. org/10.1021/jf061760h.

Nadeem, A., Alharbi, N. O., Vliagoftis, H., Tyagi, M., Ahmad, S. F., \& Sayed-Ahmed, M. M. (2015). Proteinase activated receptor-2-mediated dual oxidase-2 up-regulation is involved in enhanced airway reactivity and inflammation in a mouse model of al lergic asthma. Immunology, 145(3), 391-403. https://doi.org/10.1111/imm.12453.

Ng, T. W., Holt, P. G., \& Prescott, S. L. (2002). Cellular immune responses to ovalbumin and house dust mite in egg-allergic children. Allergy, 57(3), 207-214. https://doi. org/10.1034/j.1398-9995.2002.103369.x.

Pablos-Tanarro, A., Lopez-Exposito, I., Lozano-Ojalvo, D., Lopez-Fandino, R., \& Molina, E. (2016). Antibody production, anaphylactic signs, and T-cell responses induced by oral sensitization with ovalbumin in BALB/c and C3H/HeOuJ mice. Allergy Asthma \& Immunology Research, 8(3), 239-245. https://doi.org/10.4168/aair.2016.8.3.239.

Pène, J., Guilhot, F., Cognet, I., Guglielmi, P., Guay-Giroux, A., Bonnefoy, J. Y., .. Gauchat, J. F. (2005). Detection of $\varepsilon$ class switching and IgE synthesis in human B cells. In G. K., \& D. S.C (Eds.). Mast cells: Methods and protocols (pp. 319-329). Totowa, NJ: Humana Press. https://doi.org/https://doi.org/10.1385/1-59259-9672:319.

Pochard, P., Vickery, B., Berin, M. C., Grishin, A., Sampson, H. A., Caplan, M., et al. (2010). Targeting Toll-like receptors on dendritic cells modifies the $\mathrm{T}(\mathrm{H}) 2$ response to peanut allergens in vitro. The Journal of Allergy and Clinical Immunology, 126(1), 92-97. https://doi.org/10.1016/j.jaci.2010.04.003.

Price, D. B., Ackland, M. L., Burks, W., Knight, M. I., \& Suphioglu, C. (2014). Peanut allergens alter intestinal barrier permeability and tight junction localisation in caco-2 cell cultures. Cellular Physiology and Biochemistry, 33(6), 1758-1777. https://doi.org/ $10.1159 / 000362956$

Price, D. B., Ackland, M. L., \& Suphioglu, C. (2017). Identifying epithelial endocytotic mechanisms of the peanut allergens Ara h 1 and Ara h 2. International Archives of Allergy and Immunology, 172(2), 106-115. https://doi.org/10.1159/000451085.

Prickett, S. R., Voskamp, A. L., Dacumos-Hill, A., Symons, K., Rolland, J. M., \& O'Hehir, R. E. (2011). Ara h 2 peptides containing dominant CD4+ T-cell epitopes: Candidates for a peanut allergy therapeutic. The Journal of Allergy and Clinical Immunology, 127(3), 608-615. https://doi.org/10.1016/j.jaci.2010.09.027.

Prickett, S. R., Voskamp, A. L., Phan, T., Dacumos-Hill, A., Mannering, S. I., Rolland, J. M., et al. (2013). Ara h 1 CD4 + T cell epitope-based peptides: Candidates for a peanut allergy therapeutic. Clinical and Experimental Allergy, 43(6), 684-697. https:// doi.org/10.1111/cea.12113.

Ramadan, Q., Jafarpoorchekab, H., Huang, C. B., Silacci, P., Carrara, S., Koklu, G., ... Gijs, M. A. M. (2013). NutriChip: Nutrition analysis meets microfluidics. Lab on a Chip, 13(2), 196-203. https://doi.org/10.1039/c2lc40845g.

Ramesh, M., Yuenyongviwat, A., Konstantinou, G. N., Lieberman, J., Pascal, M., Masilamani, M., et al. (2016). Peanut T-cell epitope discovery: Ara h 1. The Journal of Allergy and Clinical Immunology, 137(6), 1764-1771. https://doi.org/10.1016/j.jaci. 2015.12.1327.

Rees, B., Spiekstra, S. W., Carfi, M., Ouwehand, K., Williams, C. A., Corsini, E., ... Gibbs, S. (2011). Inter-laboratory study of the in vitro dendritic cell migration assay for identification of contact allergens. Toxicology in Vitro, 25(8), 2124-2134. https://doi. org/10.1016/j.tiv.2011.09.021.

Remington, B., Broekman, H. C. H., Blom, W. M., Capt, A., Crevel, R. W. R., Dimitrov, I., ... Constable, A. (2018). Approaches to assess IgE mediated allergy risks (sensitization and cross-reactivity) from new or modified dietary proteins. Food and Chemical Toxicology, 112, 97-107. https://doi.org/10.1016/j.fct.2017.12.025.

Rhee, I., Zhong, M. C., Reizis, B., Cheong, C., \& Veillette, A. (2014). Control of dendritic cell migration, $\mathrm{T}$ cell-dependent immunity, and autoimmunity by protein tyrosine phosphatase PTPN12 expressed in dendritic cells. Molecular and Cellular Biology, 34(5), 888-899. https://doi.org/10.1128/mcb.01369-13.

Roth-Walter, F., Berin, M. C., Arnaboldi, P., Escalante, C. R., Dahan, S., Rauch, J., Mayer, L. (2008). Pasteurization of milk proteins promotes allergic sensitization by enhancing uptake through Peyer's patches. Allergy, 63(7), 882-890. https://doi.org/ 10.1111/j.1398-9995.2008.01673.x.

Rupa, P., Nakamura, S., Katayama, S., \& Mine, Y. (2014). Effects of ovalbumin glycoconjugates on alleviation of orally induced egg allergy in mice via dendritic-cell maturation and T-cell activation. Molecular Nutrition \& Food Research, 58(2), 405-417. https://doi.org/10.1002/mnfr.201300067.

Rytkönen, J., Valkonen, K. H., Virtanen, V., Foxwell, R. A., Kyd, J. M., Cripps, A. W., et al. (2006). Enterocyte and M-cell transport of native and heat-denatured bovine $\beta$-lactoglobulin: Significance of heat denaturation. Journal of Agricultural and Food Chemistry, 54(4), 1500-1507. https://doi.org/10.1021/jf052309d.

Saenz, S. A., Siracusa, M. C., Monticelli, L. A., Ziegler, C. G. K., Kim, B. S., Brestoff, J. R., ,.. Artis, D. (2013). IL-25 simultaneously elicits distinct populations of innate lymphoid cells and multipotent progenitor type 2 (MPPtype2) cells. Journal of Experimental Medicine, 210(9), 1823-1837. https://doi.org/10.1084/jem.20122332.

Sakaguchi, H., Inoue, R., Kaneko, H., Watanabe, M., Suzuki, K., Kato, Z., ... Kondo, N. (2002). Interaction among human leucocyte antigen-peptide-T cell receptor 
complexes in cow's milk allergy: The significance of human leucocyte antigen and T cell receptor-complementarity determining region 3 loops. Clinical and Experimental Allergy: Journal of the British Society for Allergy and Clinical Immunology, 32(5), 762-770. https://doi.org/https://doi.org/10.1046/j.1365-2222.2002.01370.x.

Saluja, R., Khan, M., Church, M. K., \& Maurer, M. (2015). The role of IL-33 and mast cells in allergy and inflammation. Clinical and Translational Allergy, 5, 33. https://doi.org/ 10.1186/s13601-015-0076-5.

Savilahti, E. M., Karinen, S., Salo, H. M., Klemetti, P., Saarinen, K. M., Klemola, T., ... Vaarala, O. (2010). Combined T regulatory cell and Th2 expression profile identifies children with cow's milk allergy. Clinical Immunology, 136(1), 16-20. https://doi.org/ 10.1016/j.clim.2010.02.011.

Sato, T., \& Clevers, H. (2013). Growing self-organizing Mini-guts from a single intestinal stem cell: Mechanism and applications. Science, 340(6137), 1190-1194. https://doi. org/10.1126/science.1234852.

Schade, R. P., Van Ieperen-Van Dijk, A. G., Van Reijsen, F. C., Versluis, C., Kimpen, J. L. L., Knol, E. F., ... Van Hoffen, E. (2000). Differences in antigen-specific T-cell responses between infants with atopic dermatitis with and without cow's milk allergy: Relevance of TH2 cytokines. Journal of Allergy and Clinical Immunology, 106(6), 1155-1162. https://doi.org/10.1067/mai.2000.110802.

Scott-Taylor, T. H., Axinia, S. C., \& Strobel, S. (2017). Lymphoproliferative responses to dendritic cell presentation of sensitizing allergens in atopic children with multiple allergies. Annals of Allergy, Asthma, \& Immunology, 119(3), 274-283. https://doi.org/ 10.1016/j.anai.2017.06.015.

Selb, R., Wal, J. M., Moreno, F. J., Lovik, M., Mills, C., Hoffmann-Sommergruber, K., et al. (2017). Assessment of endogenous allergenicity of genetically modified plants exemplified by soybean - where do we stand? Food and Chemical Toxicology, 101, 139-148. https://doi.org/10.1016/j.fct.2017.01.014.

Sicherer, S. H., \& Sampson, H. A. (2018). Food allergy: A review and update on epidemiology, pathogenesis, diagnosis, prevention, and management. The Journal of Allergy and Clinical Immunology, 141(1), 41-58. https://doi.org/10.1016/j.jaci.2017. 11.003.

Smit, J., de Zeeuw-Brouwer, M. L., van Roest, M., de Jong, G., \& van Bilsen, J. (2016). Evaluation of the sensitizing potential of food proteins using two mouse models. Toxicology Letters, 262, 62-69. https://doi.org/10.1016/j.toxlet.2016.09.005.

Smit, J. J., Pennings, M. T., Willemsen, K., van Roest, M., van Hoffen, E., \& Pieters, R. H. (2015). Heterogeneous responses and cross reactivity between the major peanut allergens Ara h 1, 2,3 and 6 in a mouse model for peanut allergy. Clinical and Translational Allergy, 5, 9. https://doi.org/10.1186/s13601-015-0056-9.

Song, C. H., Liu, Z. Q., Huang, S., Zheng, P. Y., \& Yang, P. C. (2012). Probiotics promote endocytic allergen degradation in gut epithelial cells. Biochemical and Biophysical Research Communications, 20(1), 135-140. https://doi.org/10.1016/j.bbrc.2012.08. 051.

Starkl, P., Krishnamurthy, D., Szalai, K., Felix, F., Lukschal, A., Oberthuer, D., ... JensenJarolim, E. (2011). Heating affects structure, enterocyte adsorption and signalling, as well as immunogenicity of the peanut allergen Ara h 2. The Open Allergy Journal, 4, 24-34. https://doi.org/10.2174/1874838401104010024.

Stojadinovic, M., Pieters, R., Smit, J., \& Velickovic, T. C. (2014). Cross-linking of betalactoglobulin enhances allergic sensitization through changes in cellular uptake and processing. Toxicological Sciences, 140(1), 224-235. https://doi.org/10.1093/toxsci/ kfu062.

Sullivan, K. M., Enoch, S. J., Ezendam, J., Sewald, K., Roggen, E. L., \& Cochrane, S. (2017). An adverse outcome pathway for sensitization of the respiratory tract by lowmolecular-weight chemicals: Building evidence to support the utility of in vitro and in silico methods in a regulatory context. Applied In Vitro Toxicology, 3(3), 213-226. https://doi.org/http://doi.org/10.1089/aivt.2017.0010.

Sun, C. Y., Bai, J., Hu, T. Y., Cheng, B. H., Ma, L., Fan, X. Q., ... Liu, Z. Q. (2016). CD4 + T cell responses in Balb/c mice with food allergy induced by trinitrobenzene sulfonic acid and ovalbumin. Molecular Medicine Reports, 13(6), 5349-5357. https://doi.org/ 10.3892/mmr.2016.5153.

Sun, H., Liu, X., Wang, Y. Z., Liu, J. X., \& Feng, J. (2013). Allergen-specific immunoglobulin, histamine and T-cell responses induced by soybean glycinin and betaconglycinin in BALB/c mice of oral sensitisation. Food and Agricultural Immunology, 24(4), 489-501. https://doi.org/10.1080/09540105.2012.730501.

Tao, B., Bernardo, K., Eldi, P., Chegeni, N., Wiese, M., Colella, A., ... Chataway, T. (2016). Extended boiling of peanut progressively reduces $\mathrm{IgE}$ allergenicity while retaining $\mathrm{T}$ cell reactivity. Clinical and Experimental Allergy, 46(7), 1001-1014. https://doi.org/ $10.1111 /$ cea.12740.

Tesaki, S., \& Watanabe, J. (2002). An active compound against allergen absorption in hypoallergenic wheat flour produced by enzymatic modification. Bioscience, Biotechnology, and Biochemistry, 66(9), 1930-1935. https://doi.org/10.1271/bbb.66. 1930.

Thierry, A. C., Bernasconi, E., Mercenier, A., \& Corthesy, B. (2009). Conditioned polarized Caco-2 cell monolayers allow to discriminate for the ability of gut-derived microorganisms to modulate permeability and antigen-induced basophil degranulation. Clinical and Experimental Allergy, 39(4), 527-536. https://doi.org/10.1111/j. 1365-2222.2008.03185.x.

Tiemessen, M. M., Van Ieperen-Van Dijk, A. G., Bruijnzeel-Koomen, C. A. F. M., Garssen, J., Knol, E. F., \& Van Hoffen, E. (2004). Cow's milk-specific T-cell reactivity of children with and without persistent cow's milk allergy: Key role for IL-10. The Journal of Allergy and Clinical Immunology, 113(5), 932-939. https://doi.org/10.1016/j.jaci. 2003.12.016.

Tordesillas, L., Berin, M. C., \& Sampson, H. A. (2017). Immunology of food allergy. Immunity, 47(1), 32-50. https://doi.org/10.1016/j.immuni.2017.07.004.

Tordesillas, L., Gómez-Casado, C., Garrido-Arandia, M., Murua-García, A., Palacín, A., Varela, J., ... Díaz-Perales, A. (2013). Transport of Pru p 3 across gastrointestinal epithelium - an essential step towards the induction of food allergy? Clinical and Experimental Allergy, 43(12), 1374-1383. https://doi.org/10.1111/cea.12202.

Tsuge, I., Kondo, Y., Tokuda, R., Kakami, M., Kawamura, M., Nakajima, Y., ... Urisu, A. (2006). Allergen-specific helper T cell response in patients with cow's milk allergy: Simultaneous analysis of proliferation and cytokine production by carboxyfluorescein succinimidyl ester dilution assay. Clinical and Experimental Allergy, 36(12), 1538-1545. https://doi.org/10.1111/j.1365-2222.2006.02600.x.

Tu, Y., Oluwole, C. Struiksma, S., Perdue, M. H., \& Yang, P. (2009). Mast cells modulate transport of CD23/IgE/antigen complex across human intestinal epithelial barrier. North American Journal of Medical Sciences, 1(1), 16-24.

Tu, Y., Salim, S., Bourgeois, J., Di Leo, V., Irvine, E. J., Marshall, J. K., et al. (2005). CD23mediated IgE transport across human intestinal epithelium: Inhibition by blocking sites of translation or binding. Gastroenterology, 129(3), 928-940. https://doi.org/10. 1053/j.gastro.2005.06.014.

Vissers, Y. M., Blanc, F., Skov, P. S., Johnson, P. E., Rigby, N. M., Przybylski-Nicaise, L., .. Adel-Patient, K. (2011). Effect of heating and glycation on the allergenicity of $2 S$ albumins (Ara h 2/6) from peanut. PLoS One, 6(8), e23998. https://doi.org/10.1371/ journal.pone.0023998.

Vocca, I., Canani, R. B., Camarca, A., Ruotolo, S., Nocerino, R., Radano, G., ... Gianfrani, C. (2011). Peripheral blood immune response elicited by beta-lactoglobulin in childhood cow's milk allergy. Pediatric Research, 70, 549-554. https://doi.org/10. 1203/PDR.0b013e318232739c.

Vonk, M. M., Wagenaar, L., Pieters, R. H. H., Knippels, L. M. J., Willemsen, L. E. M., Smit, J. J., ... Garssen, J. (2017). The efficacy of oral and subcutaneous antigen-specific immunotherapy in murine cow's milk- and peanut allergy models. Clinical and Translational Allergy, 7, 13. https://doi.org/10.1186/s13601-017-0170-y.

Vreeburg, R. A. M., Bastiaan-Net, S., \& Mes, J. J. (2011). Normalization genes for quantitative RT-PCR in differentiated Caco- 2 cells used for food exposure studies. Food \& Function, 2(2), 124-129. https://doi.org/10.1039/c0fo00068j.

Wai, C. Y. Y., Leung, N. Y. H., Leung, P. S. C., \& Chu, K. H. (2016). T cell epitope immunotherapy ameliorates allergic responses in a murine model of shrimp allergy. Clinical and Experimental Allergy, 46(3), 491-503. https://doi.org/10.1111/cea. 12684.

Wang, J., \& Sampson, H. A. (2009). Food allergy: Recent advances in pathophysiology and treatment. Allergy Asthma \& Immunology Research, 1(1), 19-29. https://doi.org/ 10.4168/aair.2009.1.1.19.

Westerhout, J., de Steeg, E. V., Grossouw, D., Zeijdner, E. E., Krul, C. A. M., Verwei, M., et al. (2014). A new approach to predict human intestinal absorption using porcine intestinal tissue and biorelevant matrices. European Journal of Pharmaceutical Sciences, 63, 167-177. https://doi.org/10.1016/j.ejps.2014.07.003.

Yamashita, S., Yokoyama, Y., Hashimoto, T., \& Mizuno, M. (2016). A novel in vitro coculture model comprised of Caco-2/RBL-2H3 cells to evaluate anti-allergic effects of food factors through the intestine. Journal of Immunological Methods, 435, 1-6. https://doi.org/10.1016/j.jim.2016.04.011.

Zeller, K. S., Johansson, H., Lund, T., Kristensen, N. N., Roggen, E. L., \& Lindstedt, M. (2018). An alternative biomarker-based approach for the prediction of proteins known to sensitize the respiratory tract. Toxicology in Vitro, 46, 155-162. https://doi. org/10.1016/j.tiv.2017.09.029.

Zhao, Y., Liu, D. D., Han, R., Zhang, X. D., Zhang, S. Y., \& Qin, G. X. (2015). Soybean allergen glycinin induced the destruction of the mechanical barrier function in IPEC J2. Food and Agricultural Immunology, 26(4), 601-609. https://doi.org/10.1080/ 09540105.2014.998638.

Zhao, Y., Liu, D. D., Zhang, S. Y., Pan, L., \& Qin, G. X. (2017). Different damage to the mechanical barrier function of IPEC-J2 induced by soybean allergen beta-conglycinin hydrolyzed peptides. International Journal of Food Engineering, 13(10), 7. https://doi. org/10.1515/ijfe-2016-0370.

Zhu, Z. L., Yu, J. L., Niu, Y., Sun, S. H., Liu, Y. F., Saxon, A., ... Li, W. (2016). Enhanced prophylactic and therapeutic effects of polylysine-modified Ara h 2 DNA vaccine in a mouse model of peanut allergy. International Archives of Allergy and Immunology, 171(3-4), 241-250. https://doi.org/10.1159/000453264. 